\title{
Química mineral e geotermobarometria do Batólito Serra da Água Limpa, Nappe Socorro-Guaxupé, Faixa Brasília Meridional, Sudeste do Brasil
}

\author{
Mineral chemistry and geothermobarometry of the Serra da \\ Água Limpa Batholith, Socorro-Guaxupé Nappe, Southern \\ Brasília Belt, Southeast Brazil
}

\author{
Rodrigo Vinagre ${ }^{1 *}$, Rudolph Allard Johannes Trouw ${ }^{1}$, \\ Julio Cezar Mendes ${ }^{1}$, Isabel Ludka ${ }^{1}$
}

\begin{abstract}
RESUMO: O Batólito Serra da Água Limpa, divisa dos estados de Minas Gerais e São Paulo, está relacionado ao arco magmático da margem ativa do paleocontinente Paranapanema, Faixa Brasília Meridional. Nele ocorrem feiçóes ígneas preservadas e litotipos com foliação tectônica. Aqui são apresentados dados de química mineral, com objetivo de inferir condiçóes de pressão e temperatura reinantes durante e depois da cristalização do batólito. Foram analisados cristais de plagioclásio, anfibólio, biotita e microclina. Temperaturas de cristalização calculadas pelo método de saturação de zircônio em rocha total situam-se entre 863 e $1015^{\circ} \mathrm{C}$. O cálculo da pressão mostrou valores que variam entre 5 e 6 kbar. Já o cálculo da temperatura apresentou valores distintos ao serem utilizadas análises de núcleos e bordas do anfibólio e do plagioclásio: núcleos com temperaturas mais elevadas de formação, $830-860^{\circ} \mathrm{C}$, e bordas com temperaturas entre $740-770^{\circ} \mathrm{C}$. Logo, existem três hipóteses: (A) os valores de temperatura mais altos, obtidos nos núcleos de anfibólio e plagioclásio (830 $860^{\circ} \mathrm{C}$ ), estariam relacionados à cristalizaçáo magmática, enquanto que os obtidos nas bordas $\left(740-770^{\circ} \mathrm{C}\right)$, estariam associados ao posterior metamorfismo colisional; (B) tanto os núcleos como as bordas dos cristais são produtos do metamorfismo colisional, com ápice entre $830-860^{\circ} \mathrm{C}$ e retrometamorfismo entre $740-770^{\circ} \mathrm{C}$; e (C) os núcleos e bordas dos cristais de anfibólio e plagioclásio mantiveram suas composiçóes ígneas pré-colisionais preservadas, refletindo o processo de cristalizaçáo e consolidação magmática. A primeira hipótese parece a mais provável porque é mais consistente com os dados publicados para a regiáo.
\end{abstract}

PALAVRAS-CHAVE: arco magmático; cristalização ígnea; metamorfismo colisional.

\begin{abstract}
The Serra da Água Limpa Batholith, that crops out along the boundary of Minas Gerais and São Paulo states, in Brazil, has been interpreted as part of a magmatic arc of the Paranapanema paleocontinent active margin, southern Brasília belt. Locally igneous features are preserved, but tectonic foliation is common. Mineral chemistry microprobe data are presented for plagioclase, amphibole, biotite and K-feldspar. Crystallization temperatures were calculated by the whole rock zircon saturation method, yielding values between 863 and $1015^{\circ} \mathrm{C}$. The pressure was calculated resulting in values in the range from 5 to 6 kbar. Thermometric data yielded two distinct temperature intervals: the cores of minerals rendered temperatures between $830-860^{\circ} \mathrm{C}$, and the rims from $740-770^{\circ} \mathrm{C}$. Three hypotheses may be considered: (A) the higher values obtained in the cores are related to magmatic crystallization, whereas the lower ones obtained in the rims represent metamorphism related to continental collision; (B) both cores and rims are metamorphic revealing a metamorphic peak temperature of $830-860^{\circ} \mathrm{C}$ with retrometamorphism in the range $740-770^{\circ} \mathrm{C}$; (C) cores and rims of amphibole and plagioclase crystals retained their igneous composition and reflect igneous crystallization and subsequent cooling of the magma. The first interpretation seems to be the most likely because it is consistent with other data published for the region.
\end{abstract}

KEYWORDS: magmatic arc; igneous crystallization; collisional metamorphism.

${ }^{1}$ Departamento de Geologia, Universidade Federal do Rio de Janeiro - UFRJ, Rio de Janeiro (RJ), Brasil. E-mails: rodrigogeologo@yahoo.com.br; rajtrouw@hotmail.com; julio@geologia.ufrj.br; ludka@geologia.ufrj.br

*Autor correspondente

Manuscrito ID: 30123 Recebido em: 31/05/2014. Aprovado em: 11/09/2014. 


\section{INTRODUÇÃO}

O estudo e a compreensão das rochas ígneas geradas durante um ciclo orogenético são fundamentais para o entendimento do mesmo, desde a geraçáo de magmas na fase pré-colisional até o metamorfismo das rochas magmáticas na posterior colisão continental (Wyllie 1981; Best 1982; Wilson 1991; Winter 2010).

O Batólito Serra da Água Limpa (BSAL) (Vinagre 2014; Vinagre et al. 2014) está localizado na divisa dos estados de Minas Gerais e São Paulo (Fig. 1), entre as cidades de Itajubá, em Minas Gerais, e Monteiro Lobato, em São Paulo, integrando tanto a Nappe Socorro (Campos Neto \& Caby 2000; Campos Neto et al. 2011) como o Terreno Embu (Fernandes et al. 1990; Janasi et al. 2003; Heilbron et al. 2004, 2008; Trouw et al. 2013). O BSAL foi interpretado por Vinagre et al. (2014) como produto do arco magmático instalado na margem ativa do paleocontinente Paranapanema, onde o bloco Paranapanema (Leonardos Júnior \& Fyfe 1974; Cordani et al. 1984; Mantovani et al. 2003; Mantovani \& Brito Neves 2005) representa o paleocontinente cavalgante sobre o bloco Sanfranciscano (Almeida 1977, 1981) durante a convergência e posterior colisão continental relacionada à evolução da Faixa Brasília Meridional no Neoproterozoico (Campos Neto \& Caby 2000; Trouw et al. 2000, 2013). Nesse estágio colisional, a margem ativa do paleocontinente Paranapanema evoluiu para uma espessa lasca tectônica denominada Nappe Socorro-Guaxupé (NSG, Campos Neto \& Caby 2000; Campos Neto et al. 2011), que segundo Trouw et al. (2013) inclui também o Terreno Embu.

Neste trabalho são descritos e interpretados os dados de química mineral, obtidos através de microssonda eletrônica (JEOL-JXA 8230), para três amostras do BSAL, com o objetivo de definir condiçôes de pressão e temperatura atuantes durante a cristalização magmática das rochas do BSAL e depois, no seu metamorfismo.

\section{CONTEXTO REGIONAL}

A NSG é definida como um segmento continental composto por crosta inferior e média, constituído em um ambiente de arco magmático, produzido pela subducção da placa oceânica existente entre os antigos blocos continentais São Francisco e Paranapanema (Janasi 1999; Campos Neto \& Caby 2000; Campos Neto 2000; Hackspacher et al. 2003; Campos Neto et al. 2011; Trouw et al. 2000, 2013; Vinagre et al. 2014).

O registro geológico dessa margem ativa seria o grande volume de magmatismo cálcio-alcalino, interpretado como um arco magmático, com idades que variam de 710 a $630 \mathrm{Ma}$ (Janasi et al. 2003; Campos Neto et al. 2011; Trouw et al. 2013; Vinagre et al. 2014). Dentre os corpos oriundos desse intenso processo magmático, destaca-se o BSAL (Trouw et al. 2013; Vinagre et al. 2014), ocupando uma área com mais de $700 \mathrm{~km}^{2}$ (Fig. 1B).

Tectonicamente, o BSAL ocorre tanto na Nappe Socorro como no Terreno Embu. O Terreno Embu é um compartimento tectônico localizado a sul da NSG, caracterizado por uma sucessão metassedimentar com embasamento Paleoproterozoico (Fernandes et al. 1990; Janasi et al. 2003; Heilbron et al. 2004, 2008; Trouw et al. 2013). Resultados recentes levaram a uma reinterpretação dessa região (Trouw et al. 2013). A nova hipótese considera o Terreno Embu uma continuação da Nappe Socorro, já que mapeamentos detalhados do limite entre a Nappe Socorro e o Terreno Embu revelaram uma transição gradual de um domínio para outro, com rochas similares nos dois domínios, separadas por uma zona de cisalhamento com padrão anastomosado e movimento oblíquo sobreposto por outro movimento mais novo, transcorrente dextral. Além disso, análises geocronológicas $\mathrm{U}-\mathrm{Pb}$ em zircão detrítico forneceram idades de cristalização na área fonte e de metamorfismo bastante semelhantes em amostras de rochas metassedimentares em ambos os lados da zona de cisalhamento (Duffles 2013; Trouw et al. 2013).

As características do BSAL são similares às de outros corpos estudados na NSG, como por exemplo o Complexo Socorro (Ebert et al. 1996) e o Batólito Pinhal-Ipuiúna (Haddad 1995). O seu estudo auxilia na definição do arco magmático da NSG, assim como no entendimento da sua evolução antes, durante e depois das colisóes que culminaram com a formação das faixas Brasília Meridional e Ribeira Central, no Neoproterozoico.

$\mathrm{Na}$ primeira colisão (ca. $630-600 \mathrm{Ma}$ ) a NSG representa a nappe superior em um conjunto de nappes, sendo interpretada como o bloco cavalgante no Craton São Francisco. Além de foliação metamórfica, dobras e indicadores cinemáticos indicam transporte tectônico de topo para E-NE (Campos Neto \& Caby 1999, 2000; Trouw et al. 2000; Heilbron et al. 2004; Campos Neto et al. 2004).

O metamorfismo é de alta temperatura e atingiu alta pressão na base da nappe, por volta de $12 \mathrm{kbar}$ (Del Lama et al. 2000; Campos Neto \& Caby 2000; Freitas 2000; Garcia \& Campos Neto 2003) e foi datado entre 625 e $620 \mathrm{Ma}$ pelos métodos U-Pb e Pb-Pb (Basei et al. 1995; Janasi 1999; Vlach \& Gualda 2000; Fetter et al. 2001; Negri \& Oliveira 2005; Peternel 2005). Tavares (2008) determinou para um xisto e granulitos ígneos máficos 


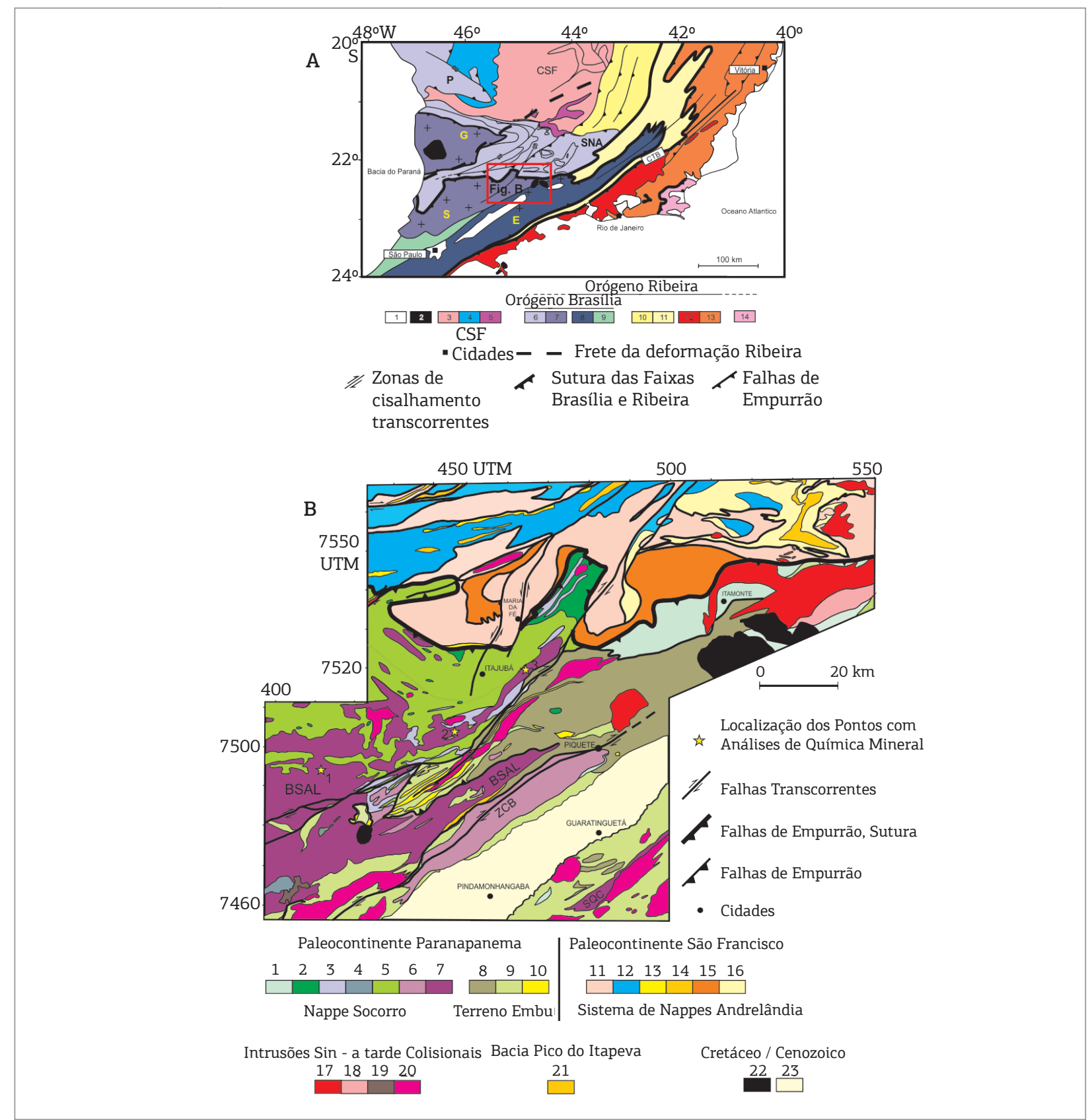

Figura 1. (A) Mapa tectônico retirado de Trouw et al. (2013). A quadrícula vermelha corresponde à área estudada. 1: Bacias Cenozoicas; 2: Plutons alcalinos Cretácicos/Cenozoicos; Craton do São Francisco e anti-país (3-5): 3: Embasamento, 4: Cobertura (Grupo Bambuí); 5: Cobertura (metassedimentos autóctones e alóctones); Orógeno Brasília (6-9); 6: Sistema de Nappes Andrelândia (SNA) e Nappe Passos (P); 7: Nappe Socorro (S)-Guaxupé (G); 8: Terreno Embu (E)-Paraíba do Sul (PS); 9: Terreno Apiaí; Orógeno Ribeira (10-14); 10: Domínio Externo; 11: Domínio Juiz de Fora; 12: Arco Rio Negro (Terreno Oriental); 13: Terreno Oriental; 14: Terreno Cabo Frio. Observar a zona de interferência entre os orógenos Brasília e Ribeira, limitada pela linha tracejada que representa a frente do cinturão Ribeira. (B) Mapa geológico simplificado da região, retirado de Trouw et al. (2013). Nappe Socorro (1-7); 1: Embasamento Paleoproterozoico na Nappe Socorro e no Terreno Embu; 2: Granulito com ortopiroxênio; 3: Granada sillimanita xisto; 4: Granada cordierita gnaisse; 5: Gnaisse bandado; 6: Hornblenda Ortognaisse; 7: Batólito Serra da Água Limpa (BSAL); Terreno Embu (8-10); 8: Predominância de paragnaisses; 9: Xisto com predominância de biotita; 10: Quartzito; Sistema de Nappes Andrelândia (11-16); 11: Fatias de embasamento Paleoproterozoico; 12: Unidade de São Vicente, paragnaisses; 13: Quartzito; 14: Unidade de Santo Antônio, biotita xistos; 15: Unidade Arantina, Cianita K-feldspato gnaisses, xistos de granulação grossa e gnaisses; intrusões Sin-tarde colisionais (17-20); 17: Granito com as idades entre 610 - $600 \mathrm{Ma}$; 18: Granitos com idades entre 600 - $590 \mathrm{Ma}$; 19: Granito com idades entre 590 - $580 \mathrm{Ma}$; 20: Granito com idades na faixa de 580 $570 \mathrm{Ma}$; 21: Metassedimentos da bacia Pico do Itapeva (570 - $540 \mathrm{Ma);} \mathrm{22:} \mathrm{Intrusão} \mathrm{alcalina} \mathrm{Cretáceo/Cenozoico;} \mathrm{23:}$ Bacia de Taubaté (Cenozoico); ZSB, Zona de cisalhamento Buquira; SQC, Batólito Serra do Quebra-Cangalha. 
localizados na base da Nappe Socorro temperaturas de formação por volta de $915^{\circ} \mathrm{C}$, aliada a uma pressão de aproximadamente $8 \mathrm{kbar}$. $\mathrm{Na}$ Unidade Intermediária da nappe, a pressão não ultrapassa 7 kbar e as temperaturas são altas, por volta de $900^{\circ} \mathrm{C}$ (Oliveira \& Ruberti 1979; Vasconcellos et al. 1991; Negri 2002; Negri \& Oliveira 2005; Campos Neto et al. 2004, 2011).

Assim sendo, o metamorfismo é caracterizado por altas temperaturas tanto na base como na porção intermediária da nappe, enquanto que a pressão varia consideravelmente diminuindo da porção basal para níveis crustais mais intermediários. Esse alto fluxo de calor com pouca ou nenhuma variação tanto na base da nappe como nos níveis crustais intermediários é considerado muito semelhante aos ocorrentes nos arcos magmáticos modernos (Campos Neto et al. 2011).

\section{METODOLOGIA}

As análises de química mineral foram realizadas no LABSONDA, Departamento de Geologia da Universidade Federal do Rio de Janeiro (UFRJ), por meio de microssonda eletrônica JEOL JXA-8230 dotada de cinco espectrômetros e oito cristais analisadores, que funciona segundo o método explicado por Gomes (1984). As condiçôes analíticas foram: voltagem do feixe eletrônico de $15.0 \mathrm{kV}$, corrente do filamento de $20 \mathrm{nA}$; nas análises quantitativas o diâmetro de feixe eletrônico foi de $10 \mu \mathrm{m}$ e a forma tipo círculo; nas análises para geração de mapas a forma do feixe eletrônico foi tipo SPOT.

\section{SÍNTESE DA GEOLOGIA, GEOQUÍMICA E GEOCRONOLOGIA DO BATÓLITO SERRA DA ÁGUA LIMPA}

O BSAL ocorre alongado na direção NE-SW, porém mostrando diversas ramificaçôes, principalmente no seu limite norte (Fig. 1B). Controla a morfologia local, se destacando no relevo devido a maior resistência à alteração intempérica.

$\mathrm{O}$ aspecto de campo é de um granitoide inequigranular porfirítico (Fig. 2A) normalmente com foliação metamórfica incipiente, e de um ortognaisse oftálmico (Fig. 2B) com texturas que podem chegar a protomiloníticas (Fig. 2C), miloníticas (Fig. 2D) e ultramiloníticas (Fig. 2D). Os fenocristais são predominantemente de microclina e raro plagioclásio, ambos variando de 1,5 a $15 \mathrm{~cm}$ de comprimento. Sua textura porfirítica é bastante diversificada em função de variaçóes na abundância, no tamanho e na forma dos fenocristais. A matriz contém quartzo, em alguns pontos azulado, microclina, plagioclásio e biotita, podendo ou não ter anfibólio. São rochas cinzentas, mas podem ser rosa claro e localmente esverdeadas. O caráter intrusivo é definido por apófises, xenólitos, diques e tetos pendentes (Vinagre et al. 2014).

A proporçáo e a cor dos fenocristais permitiu reconhecer no campo cinco fácies texturais distintas. Frequentemente, uma fácies grada para outra em escala métrica. São elas: Fácies 1 - abundante matriz e $<20 \%$ de fenocristais rosados; Fácies 2 - abundante matriz com hornblenda e $<20 \%$ de fenocristais cinzentos; Fácies 3 - porfirítica com 20 a 60\% de fenocristais rosados; Fácies 4 - porfirítica com hornblenda e 20 a $60 \%$ de fenocristais cinzentos; e Fácies 5 - porfirítica com hornblenda e 20 a $60 \%$ de fenocristais esverdeados (Vinagre et al. 2014).

Segundo Vinagre et al. (2014), análises litogeoquímicas mostraram que as rochas do BSAL possuem composiçóes monzonítica, quartzo-monzonítica, granodiorítica e granítica (Fig. 3A), com assinatura álcali-cálcica a cálcio-alcalina (Figs 3B e 3C), sendo metaluminosas do tipo I, porém com ligeira tendência peraluminosa (Fig. 3D). Diagramas de ambiência geotectônica indicam que as rochas do batólito foram produzidas em ambiente de arco vulcânico, o que é confirmado por anomalias negativas de elementos HFS (elementos de alto potencial iônico) em diagramas multielementar. Análises de isótopos $\mathrm{Sm}-\mathrm{Nd}$ em rocha total apontam valores de $\varepsilon_{\mathrm{Nd}}$ altamente negativos $\left(\varepsilon_{\mathrm{Nd}\{\mathrm{T}\}},-12 \mathrm{a}-7\right)$ para as amostras do BSAL, indicando que essas amostras sofreram forte contaminação crustal ou são produtos de fusão da crosta inferior.

Idades U-Pb em zircão (LA-ICP-MS) apontaram que as rochas do BSAL cristalizaram ao longo de $40 \mathrm{Ma}$, entre 670 e $630 \mathrm{Ma}$, predominando 645 - $630 \mathrm{Ma}$ (Vinagre et al. 2014).

Uma vez que a maioria dos afloramentos possui foliação metamórfica bem desenvolvida, as rochas do BSAL exibem evidências de recristalização metamórfica, tais como fenocristais amendoados e com sombra de pressão, geração de novos grãos e matriz recristalizada. Além disso, o metamorfismo que afetou as rochas do BSAL está evidenciado nas bordas dos cristais de zircão, que localmente mostram um sobrecrescimento com idades U-Pb (LA-ICP-MS) variando entre 625 e $600 \mathrm{Ma}$ (Vinagre et al. 2014), intervalo que corresponde, nessa região, à colisão entre os paleocontinentes Paranapanema e São Francisco (Trouw 2008; Campos Neto et al. 2011; Trouw et al. 2013). 

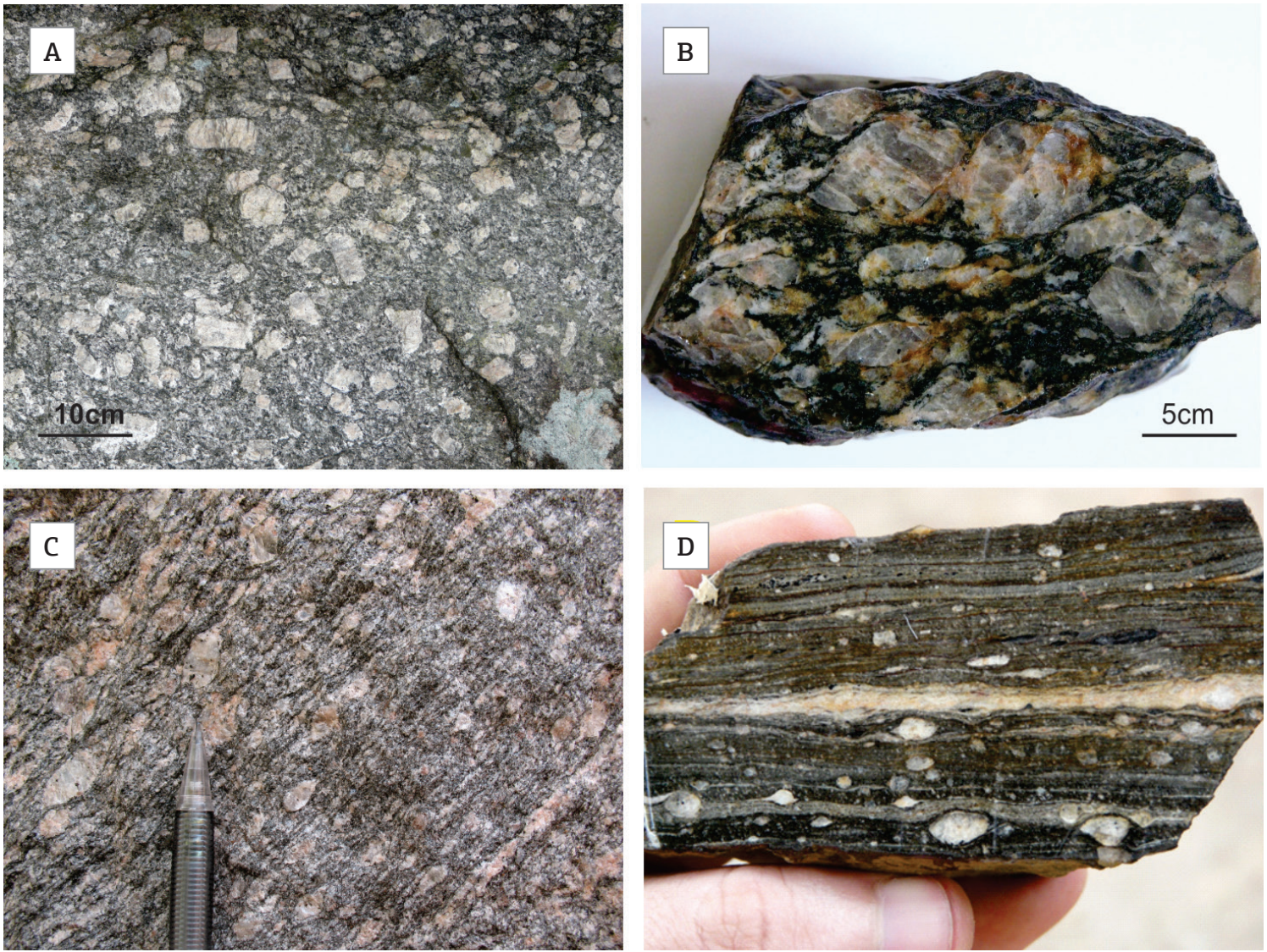

Figura 2. (A) Granitoide inequigranular porfirítico aparentemente isotrópico, Batólito Serra da Água Limpa; (B) Ortognaisse oftálmico, Batólito Serra da Água Limpa; (C) Ortognaisse protomilonítico, Batólito Serra da Água Limpa; (D) Rocha do Batólito Serra da Água Limpa exibindo textura milonítica com níveis ultramiloníticos.

\section{PETROGRAFIA DAS FÁCIES}

A descrição petrográfica a seguir foi realizada com base no estudo de 29 lâminas delgadas (Tab. 1). Devido à similaridade textural e mineralógica das rochas do BSAL em lâmina, as cinco fácies foram agrupadas em uma única descrição, que aponta, quando existentes, as diferenças entre as mesmas.

A análise modal dessas lâminas mostra que a composição do corpo batolítico, matriz mais fenocristais, varia principalmente entre quartzo sienito, quartzo monzonito, sienogranito e monzogranito (Vinagre et al. 2014) (Fig. 4). Vale a pena ressaltar que a análise modal de rochas megaporfiríticas é menos precisa e pode resultar em maior espalhamento na classificação.

Em geral, as rochas têm textura inequigranular do tipo porfirítica com fenocristais predominantemente compostos por microclina (Figs. 5A e 5B) e raro plagioclásio.
Os fenocristais são euédricos com forma tabular nos afloramentos onde a textura magmática ocorre aparentemente preservada e subédricos a anédricos amendoados nos afloramentos onde a rocha possui evidente foliação tectônica.

A matriz (Fig. 5C) tem granulação média a grossa e varia de xenomórfica a hipidiomórfica seriada. É composta essencialmente por plagioclásio, microclina, biotita e quartzo, sendo titanita, allanita, minerais opacos, apatita e zircão, acessórios; hornblenda é fase varietal. Epídoto, titanita, mica branca, além de alguns cristais de hornblenda, biotita e minerais opacos são interpretados como produtos de cristalização metamórfica e representam fases secundárias.

O plagioclásio, que na matriz é mais abundante do que a microclina, é anédrico, raramente subédrico. Pode mostrar extinção ondulante e uma incipiente recuperação para subgrãos em alguns cristais. Tem como principal produto de alteração retrometamórfica pequenos 

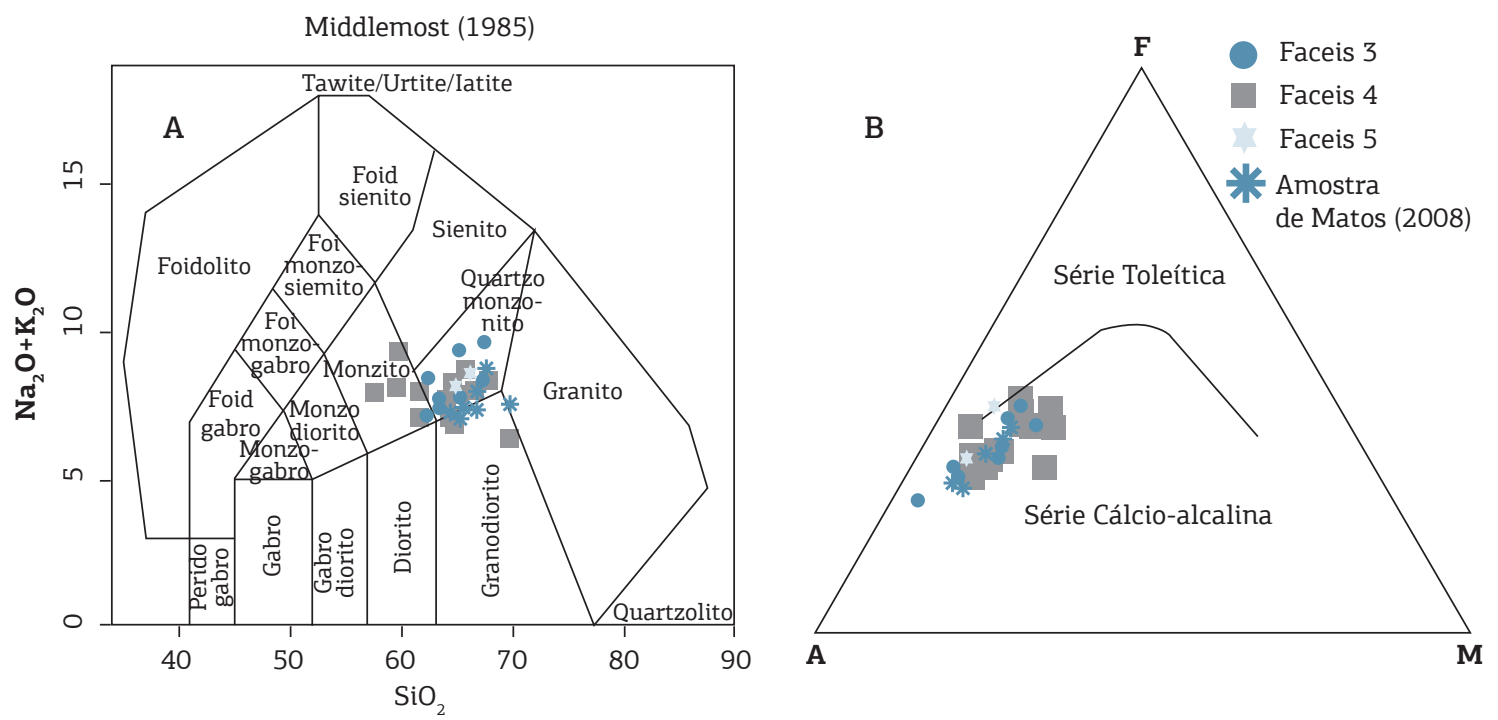

A/CNK-A/NK (Shand 1943)
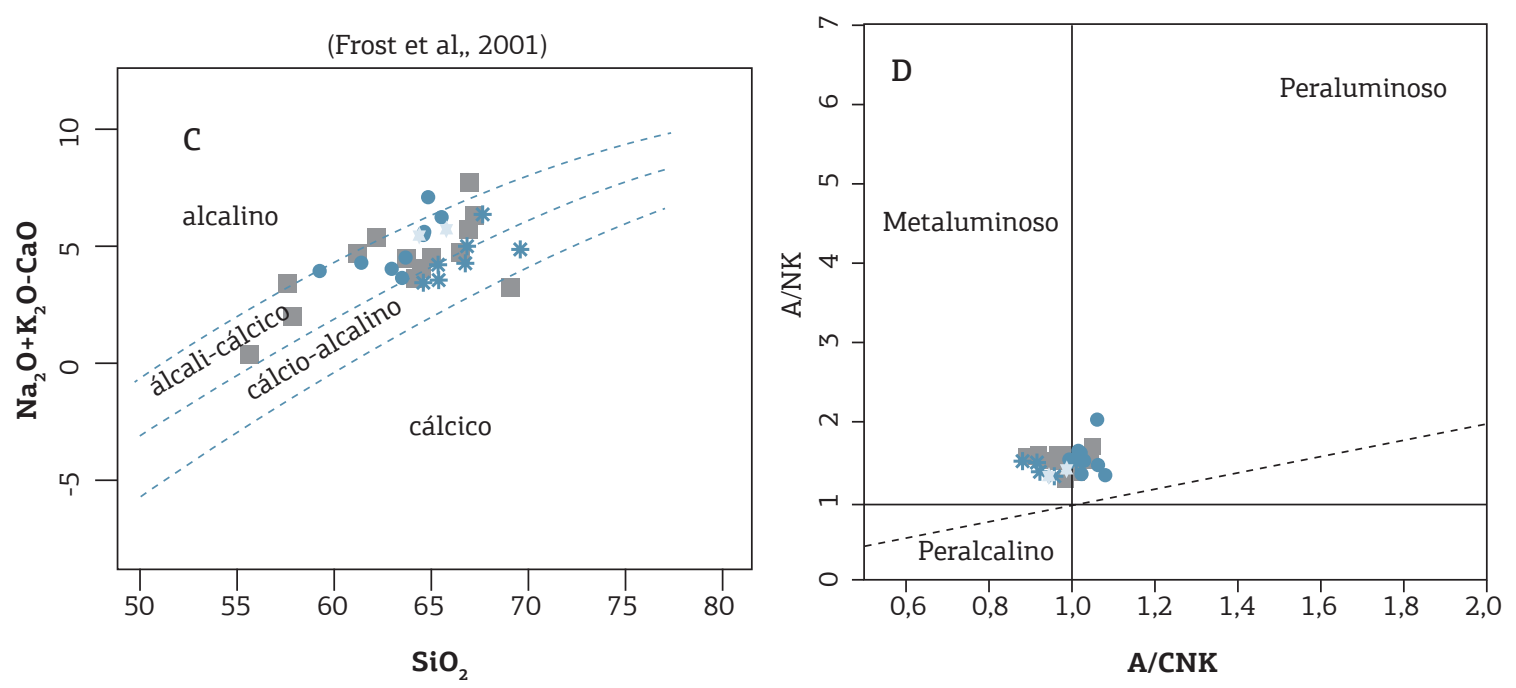

Figura 3. (A) Diagrama de Middlemost (1985), mostrando que as amostras da Fácies 3 (círculo) plotam predominantemente no campo dos quartzo-monzonitos, assim como as da Fácies 5 (estrela) e as de Matos, 2008 (asterisco). As amostras da Fácies 4 (quadrado) plotam nos campos monzonito, quartzo-monzonito e granodiorito. (B) Diagrama AFM, onde se pode ver a tendência aluminosa das amostras do Batólito Serra da Água Limpa, todas compondo um trend na série cálcio-alcalina. (C) Diagrama de Frost et al. (2001) mostrando que as rochas do Batólito Serra da Água Limpa possuem assinaturas álcali-cálcica a cálcio-alcalina. (D) Diagrama de Shand (1943), mostrando que as amostras do Batólito Serra da Água Limpa estão concentradas no limite entre os campos Meta e Peraluminosos. As amostras da Fácies 3 (círculo) tendem a ser ligeiramente peraluminosas, enquanto que as das Fácies 4 (quadrado), 5 (estrela) e as amostras de Matos (2008) (asterisco), tendem a ser metaluminosas.

grãos de epídoto. A microclina tem as mesmas características texturais do plagioclásio. São comuns lamelas de exsolução. Altera basicamente para mica branca e tem quartzo, biotita, minerais opacos, apatita e zircâo como inclusôes. Duas geraçôes de biotita foram identificadas: uma primária, anédrica a subédrica, e outra posterior, com aparência subédrica a euédrica que substitui a primária nos domínios de borda e ao longo da clivagem do mineral. As duas geraçôes mostram substituiçôes para titanita, fases opacas e epídoto quando em contato com 
Tabela 1. Análise modal (\%), a partir da contagem de 600 pontos, de 29 amostras de rochas do Batólito Serra da Água Limpa

\begin{tabular}{|c|c|c|c|c|c|c|c|c|c|c|}
\hline \multirow{2}{*}{ Fase mineral } & \multirow{2}{*}{$\begin{array}{c}\text { Fácies } \\
1\end{array}$} & \multirow{2}{*}{$\begin{array}{c}\text { Fácies } \\
2 \\
\text { MLR } \\
357\end{array}$} & \multicolumn{8}{|c|}{ Fácies 3} \\
\hline & & & $\begin{array}{c}\text { RDPA } \\
\mathbf{4 4}\end{array}$ & $\begin{array}{c}\text { RDPA } \\
46\end{array}$ & $\begin{array}{c}\text { RDIT } \\
54\end{array}$ & $\begin{array}{l}\text { VAC } \\
507\end{array}$ & $\begin{array}{c}\text { MLR } \\
17\end{array}$ & $\begin{array}{c}\text { RDPA } \\
57\end{array}$ & $\begin{array}{c}\text { RDTM } \\
53\end{array}$ & $\begin{array}{c}\text { RDCJ } \\
24\end{array}$ \\
\hline Quartzo & 21,6 & 23,7 & 3,4 & 16,4 & 15,8 & 29,6 & 17,0 & 17,6 & 10,1 & 15,0 \\
\hline K-feldspato & 34,8 & 27,4 & 49,0 & 45,8 & 56,6 & 43,8 & 49,5 & 51,3 & 48,4 & 36,8 \\
\hline Biotita & 11,9 & 6,8 & 22,5 & 14,1 & 8,6 & 6,0 & 14,0 & 7,5 & 15,1 & 21,6 \\
\hline Plagioclásio & 28,2 & 38,1 & 20,8 & 20,2 & 15,0 & 19,9 & 17,6 & 21,6 & 23,6 & 14,3 \\
\hline Allanita & $\operatorname{tr}$ & $\operatorname{tr}$ & $\operatorname{tr}$ & $\operatorname{tr}$ & $\operatorname{tr}$ & $\operatorname{tr}$ & 0,2 & 0,0 & $\operatorname{tr}$ & $\operatorname{tr}$ \\
\hline Epidoto & 2,3 & 1,4 & 0,4 & 1,8 & 1,7 & $\operatorname{tr}$ & 0,7 & 0,2 & 1,0 & 5,9 \\
\hline Hornblenda & - & $\operatorname{tr}$ & - & - & - & - & - & - & - & - \\
\hline Minerais opacos & $\operatorname{tr}$ & 1,4 & 3,4 & 0,9 & 2,1 & $\operatorname{tr}$ & 0,4 & 1,5 & $\operatorname{tr}$ & 5,5 \\
\hline Mica branca & $\operatorname{tr}$ & 0,9 & 0,2 & 0,2 & $\operatorname{tr}$ & 0,4 & $\operatorname{tr}$ & $\operatorname{tr}$ & 0,7 & 0,8 \\
\hline Titanita & 1,2 & $\operatorname{tr}$ & $\operatorname{tr}$ & 0,5 & $\operatorname{tr}$ & 0,2 & 0,7 & 0,2 & 0,7 & $\operatorname{tr}$ \\
\hline Apatita & $\operatorname{tr}$ & 0,3 & $\operatorname{tr}$ & 0,1 & 0,2 & $\operatorname{tr}$ & $\operatorname{tr}$ & $\operatorname{tr}$ & 0,4 & $\operatorname{tr}$ \\
\hline Zircão & $\operatorname{tr}$ & $\operatorname{tr}$ & 0,2 & $\operatorname{tr}$ & $\operatorname{tr}$ & $\operatorname{tr}$ & $\operatorname{tr}$ & $\operatorname{tr}$ & $\operatorname{tr}$ & 0,2 \\
\hline \multicolumn{11}{|l|}{ Streckeisen (\%) } \\
\hline Q & 25,5 & 26,6 & 4,7 & 19,9 & 18,1 & 31,7 & 20,3 & 19,4 & 12,3 & 22,6 \\
\hline A & 41,2 & 30,7 & 66,9 & 55,5 & 64,8 & 47,0 & 58,9 & 56,7 & 58,9 & 55,7 \\
\hline$P$ & 33,3 & 42,7 & 28,4 & 24,5 & 17,1 & 21,3 & 20,9 & 23,9 & 28,7 & 21,7 \\
\hline & \multicolumn{10}{|c|}{ Fácies 4} \\
\hline Fase mineral & VAC 11 & $\begin{array}{c}\text { RDPA } \\
75\end{array}$ & $\begin{array}{c}\text { RDPA } \\
45\end{array}$ & VAC 10 & VAC 8 & $\begin{array}{l}\text { RDTM } \\
52\end{array}$ & $\begin{array}{c}\text { RDPA } \\
47\end{array}$ & $\begin{array}{c}\text { MLR } \\
50\end{array}$ & $\begin{array}{c}\text { RDIT } \\
70\end{array}$ & $\begin{array}{c}\text { MLR } \\
410\end{array}$ \\
\hline Quartzo & 3,0 & 10,1 & 6,9 & 19,6 & 15,0 & 11,4 & 21,0 & 8,6 & 19,0 & 8,0 \\
\hline K-feldspato & 48,9 & 37,8 & 45,6 & 44,5 & 55,2 & 42,9 & 42,2 & 45,1 & 38,4 & 45,6 \\
\hline Biotita & 2,8 & 17,3 & 13,8 & 8,5 & 7,2 & 10,5 & 10,1 & 10,1 & 7,3 & 17,7 \\
\hline Plagioclásio & 39,4 & 17,7 & 22,8 & 25,5 & 21,6 & 29,6 & 18,9 & 29,4 & 22,3 & 24,9 \\
\hline Allanita & $\operatorname{tr}$ & $\operatorname{tr}$ & $\operatorname{tr}$ & $\operatorname{tr}$ & $\operatorname{tr}$ & $\operatorname{tr}$ & $\operatorname{tr}$ & $\operatorname{tr}$ & $\operatorname{tr}$ & $\operatorname{tr}$ \\
\hline Epidoto & 0,4 & 2,8 & 2,3 & $\operatorname{tr}$ & 0,2 & 0,8 & 0,8 & 3,0 & 0,0 & 1,7 \\
\hline Hornblenda & 2,8 & 9,9 & 5,9 & 1,0 & 0,8 & 1,5 & 5,6 & 2,1 & 7,5 & 1,3 \\
\hline Minerais opacos & 2,3 & 4,1 & 1,3 & 0,7 & $\operatorname{tr}$ & 2,0 & 1,3 & 1,3 & 2,6 & 0,2 \\
\hline Mica branca & 0,2 & 0,2 & 0,4 & $\operatorname{tr}$ & $\operatorname{tr}$ & $\operatorname{tr}$ & $\operatorname{tr}$ & $\operatorname{tr}$ & $\operatorname{tr}$ & 0,4 \\
\hline Titanita & $\operatorname{tr}$ & $\operatorname{tr}$ & 1,0 & $\operatorname{tr}$ & $\operatorname{tr}$ & 1,3 & $\operatorname{tr}$ & 0,2 & 2,1 & 0,2 \\
\hline Apatita & $\operatorname{tr}$ & $\operatorname{tr}$ & $\operatorname{tr}$ & 0,2 & $\operatorname{tr}$ & $\operatorname{tr}$ & $\operatorname{tr}$ & $\operatorname{tr}$ & 0,7 & $\operatorname{tr}$ \\
\hline Zircão & 0,2 & $\operatorname{tr}$ & $\operatorname{tr}$ & $\operatorname{tr}$ & $\operatorname{tr}$ & $\operatorname{tr}$ & $\operatorname{tr}$ & $\operatorname{tr}$ & $\operatorname{tr}$ & $\operatorname{tr}$ \\
\hline \multicolumn{11}{|l|}{ Streckeisen (\%) } \\
\hline Q & 3,3 & 15,4 & 9,2 & 21,8 & 16,4 & 13,6 & 25,6 & 10,4 & 23,8 & 10,2 \\
\hline A & 53,6 & 57,5 & 60,6 & 49,7 & 60,1 & 51,1 & 51,4 & 54,2 & 48,2 & 58,1 \\
\hline $\mathrm{P}$ & 43,1 & 27,0 & 30,2 & 28,5 & 23,6 & 35,3 & 23,0 & 35,4 & 28,0 & 31,7 \\
\hline
\end{tabular}


Tabela 1. Continuação

\begin{tabular}{|c|c|c|c|c|c|c|c|c|c|}
\hline \multirow{2}{*}{ Fase mineral } & \multicolumn{2}{|c|}{ Fácies 5} & \multicolumn{7}{|c|}{ Amostras de Matos (2008) } \\
\hline & RDIT 41 & $\begin{array}{c}\text { MLR } \\
138\end{array}$ & GI 139 & GM 134 & GI 70 & GI 180 & GM 35 & GM 133 & GM 135 \\
\hline Quartzo & 15,2 & 14,7 & 29,0 & 40,3 & 28,3 & 26,0 & 19,6 & 21,6 & 20,3 \\
\hline K-feldspato & 47,1 & 37,8 & 23,2 & 21,6 & 27,6 & 17,6 & 22,0 & 27,0 & 22,0 \\
\hline Biotita & 7,0 & 22,1 & 7,7 & 2,6 & 6,3 & 5,3 & 5,0 & 10,3 & 8,6 \\
\hline Plagioclásio & 23,3 & 21,0 & 36,2 & 16,0 & 26,6 & 27,6 & 45,0 & 29,6 & 28,6 \\
\hline Allanita & $\operatorname{tr}$ & $\operatorname{tr}$ & $\operatorname{tr}$ & $\operatorname{tr}$ & $\operatorname{tr}$ & $\operatorname{tr}$ & $\operatorname{tr}$ & $\operatorname{tr}$ & $\operatorname{tr}$ \\
\hline Epidoto & 0,3 & 2,3 & $\operatorname{tr}$ & $\operatorname{tr}$ & $\operatorname{tr}$ & $\operatorname{tr}$ & $\operatorname{tr}$ & $\operatorname{tr}$ & 0,6 \\
\hline Hornblenda & 3,1 & 1,7 & 2,7 & 11,6 & 7,6 & 23,0 & 8,3 & 11,3 & 19,6 \\
\hline Minerais opacos & 2,4 & 0,4 & $\operatorname{tr}$ & $\operatorname{tr}$ & 2,0 & $\operatorname{tr}$ & $\operatorname{tr}$ & $\operatorname{tr}$ & $\operatorname{tr}$ \\
\hline Mica branca & $\operatorname{tr}$ & $\operatorname{tr}$ & $\operatorname{tr}$ & $\operatorname{tr}$ & $\operatorname{tr}$ & $\operatorname{tr}$ & $\operatorname{tr}$ & $\operatorname{tr}$ & $\operatorname{tr}$ \\
\hline Titanita & 1,4 & $\operatorname{tr}$ & $\operatorname{tr}$ & 7,3 & 0,6 & $\operatorname{tr}$ & $\operatorname{tr}$ & $\operatorname{tr}$ & $\operatorname{tr}$ \\
\hline Apatita & 0,1 & $\operatorname{tr}$ & 1,0 & $\operatorname{tr}$ & $\operatorname{tr}$ & $\operatorname{tr}$ & $\operatorname{tr}$ & $\operatorname{tr}$ & $\operatorname{tr}$ \\
\hline Zircão & 0,2 & $\operatorname{tr}$ & $\operatorname{tr}$ & 0,3 & $\operatorname{tr}$ & $\operatorname{tr}$ & $\operatorname{tr}$ & $\operatorname{tr}$ & $\operatorname{tr}$ \\
\hline \multicolumn{10}{|l|}{ Streckeisen (\%) } \\
\hline$Q$ & 17,8 & 20,0 & 32,8 & 51,7 & 34,3 & 36,5 & 22,6 & 27,6 & 28,6 \\
\hline A & 55,0 & 51,4 & 26,2 & 27,7 & 33,5 & 24,7 & 25,4 & 34,5 & 31,0 \\
\hline $\mathrm{P}$ & 27,2 & 28,6 & 41,0 & 20,5 & 32,2 & 38,8 & 52,0 & 37,9 & 40,3 \\
\hline
\end{tabular}

tr: traço; Q: quartzo; A: álcalis; P: plagioclásio. Os dados de Matos (2008) foram obtidos a partir da contagem de 300 pontos.

plagioclásio. Plagioclásio, fases opacas, apatita e zircão podem aparecer como inclusóes na biotita. $\mathrm{O}$ quartzo anédrico normalmente tem inclusôes de feldspatos, biotita, titanita, zircão, apatita e fases opacas. Apresenta de pouca a intensa extinção ondulante com recuperação para subgrãos e recristalização para novos grãos (Fig. 5D). A hornblenda (Fig. 5E), presente apenas nas fácies 2, 4 e 5 , varia de anédrica a subédrica e representa a fase mineral máfica predominante nas rochas dessas fácies. Tem contatos sinuosos com os demais minerais, cor natural verde oliva e pleocroismo variando de verde escuro a claro, porém, alguns cristais possuem, principalmente em domínios de borda, cor natural verde azulada. Comumente está associada à biotita, fases opacas e epídoto, que ocorrem em domínios de borda e ao longo das clivagens. Em geral os cristais de hornblenda possuem inclusões milimétricas a submilimétricas de plagioclásio, fases opacas, titanita, zircão e apatita. A allanita (Fig. 5F), rara, é subédrica a euédrica e dispersa na rocha. O epídoto é metamórfico e normalmente está associado a plagioclásio, K-feldspato e biotita. Foram identificadas duas geraçôes de titanita e minerais opacos, uma primária comumente dispersa na matriz e outra posterior.

\section{QUÍMICA MINERAL E GEOTERMOBAROMETRIA DO BATÓLITO SERRA DA ÁGUA LIMPA}

Para essas análises foram selecionadas três amostras, duas correspondem à Fácies 4 (RDPA 75 e VAC 11) e uma à Fácies 5 (RDIT 41). Essas amostras foram escolhidas por terem plagioclásio e hornblenda na sua associação mineral, pois esse par permite cálculos de pressões e temperaturas estimadas na sua formação. A amostra RDPA 75 representa um granitoide sem foliação, enquanto que as amostras VAC 11 e RDIT 41 possuem nítida foliação tectônica.

\section{Química mineral}

As análises químicas das fases minerais anfibólio, plagioclásio, biotita e microclina mostraram grande semelhança 
Tabela 2. Composições químicas de anfibólio para três amostras de rochas do Batólito Serra da Água Limpa (RDPA 75, VAC 11 e RDIT 41), totalizando 19 cristais, onde C representa a porção mais central dos grãos e B os domínios de borda

\begin{tabular}{|c|c|c|c|c|c|c|}
\hline \multirow{2}{*}{$\begin{array}{l}\text { Amostras } \\
\text { Grão }\end{array}$} & \multicolumn{6}{|c|}{ RDPA 75} \\
\hline & CA_HBL & CD_HBL & CB_HBL & CB_HBL & CA_HBL_A & CA_HBL_A \\
\hline Local analisado & C & C & C & B & C & B \\
\hline $\mathrm{SiO}_{2}$ & 42,73 & 42,16 & 43,14 & 43,30 & 42,30 & 44,20 \\
\hline $\mathrm{TiO}_{2}$ & 1,95 & 1,83 & 2,00 & 1,95 & 1,97 & 2,00 \\
\hline $\mathrm{Al}_{2} \mathrm{O}_{3}$ & 9,26 & 9,59 & 9,51 & 9,37 & 9,49 & 9,29 \\
\hline $\mathrm{FeO}$ & 15,94 & 16,28 & 15,66 & 15,35 & 15,96 & 15,60 \\
\hline $\mathrm{MnO}$ & 0,50 & 0,44 & 0,52 & 0,44 & 0,45 & 0,43 \\
\hline $\mathrm{MgO}$ & 11,72 & 11,92 & 11,87 & 11,69 & 10,84 & 11,70 \\
\hline $\mathrm{CaO}$ & 11,38 & 11,47 & 11,23 & 11,47 & 11,22 & 11,64 \\
\hline $\mathrm{Na}_{2} \mathrm{O}$ & 1,70 & 1,58 & 1,83 & 1,46 & 1,56 & 1,45 \\
\hline $\mathrm{K}_{2} \mathrm{O}$ & 1,80 & 1,75 & 1,87 & 1,72 & 1,84 & 1,77 \\
\hline Total (\% mas) & 96,97 & 97,02 & 97,60 & 96,76 & 95,63 & 98,06 \\
\hline $\mathrm{Si}$ & 6,47 & 6,36 & 6,49 & 6,55 & 6,52 & 6,60 \\
\hline $\mathrm{Al}^{\mathrm{IV}}$ & 1,53 & 1,64 & 1,52 & 1,46 & 1,48 & 1,40 \\
\hline $\mathrm{Al}^{\mathrm{VI}}$ & 0,12 & 0,07 & 0,17 & 0,21 & 0,24 & 0,23 \\
\hline $\mathrm{Ti}$ & 0,22 & 0,21 & 0,23 & 0,22 & 0,23 & 0,22 \\
\hline $\mathrm{Fe}^{3+}$ & 0,28 & 0,51 & 0,26 & 0,21 & 0,18 & 0,17 \\
\hline $\mathrm{Fe}^{2+}$ & 1,70 & 1,51 & 1,65 & 1,69 & 1,83 & 1,74 \\
\hline $\mathrm{Mg}$ & 2,65 & 2,68 & 2,66 & 2,63 & 2,49 & 2,60 \\
\hline $\mathrm{Mn}$ & 0,03 & 0,03 & 0,03 & 0,03 & 0,03 & 0,03 \\
\hline $\mathrm{Fe}^{2+}$ & 0,04 & 0,04 & 0,06 & 0,04 & 0,04 & 0,04 \\
\hline $\mathrm{Mn}$ & 0,03 & 0,03 & 0,03 & 0,03 & 0,03 & 0,03 \\
\hline $\mathrm{Ca}$ & 1,85 & 1,86 & 1,81 & 1,86 & 1,85 & 1,86 \\
\hline $\mathrm{Na}$ & 0,08 & 0,08 & 0,10 & 0,08 & 0,08 & 0,07 \\
\hline $\mathrm{Na}$ & 0,42 & 0,38 & 0,43 & 0,35 & 0,39 & 0,35 \\
\hline K & 0,35 & 0,34 & 0,36 & 0,33 & 0,36 & 0,34 \\
\hline Total (cat) & 15,76 & 15,72 & 15,79 & 15,68 & 15,75 & 15,68 \\
\hline 0 & 23 & 23 & 23 & 23 & 23 & 23 \\
\hline $\mathrm{X}_{\mathrm{Mg}}$ & 0,61 & 0,64 & 0,62 & 0,61 & 0,58 & 0,40 \\
\hline \multicolumn{4}{|l|}{ Amostras } & \multicolumn{3}{|c|}{ VAC 11} \\
\hline Grão & HBL_01 & \multicolumn{2}{|l|}{ HBL_01 } & \multicolumn{2}{|r|}{ HBL_10 } & HBL_10A \\
\hline Local analisado & C & B & \multicolumn{2}{|c|}{ C } & C & C \\
\hline $\mathrm{SiO}_{2}$ & 41,45 & 42,10 & \multicolumn{2}{|c|}{41,32} & 41,58 & 41,12 \\
\hline $\mathrm{TiO}_{2}$ & 1,84 & 1,90 & \multicolumn{2}{|c|}{1,74} & 1,76 & 1,72 \\
\hline $\mathrm{Al}_{2} \mathrm{O}_{3}$ & 10,43 & 10,27 & \multicolumn{2}{|c|}{10,61} & 10,57 & 10,60 \\
\hline $\mathrm{FeO}$ & 18,46 & 18,13 & \multicolumn{2}{|c|}{18,71} & 18,57 & 18,33 \\
\hline
\end{tabular}


Tabela 2. Continuação

\begin{tabular}{|c|c|c|c|c|c|c|c|}
\hline \multirow{2}{*}{$\begin{array}{l}\text { Amostras } \\
\text { Grão }\end{array}$} & \multicolumn{7}{|c|}{ VAC 11} \\
\hline & \multicolumn{2}{|c|}{ HBL_01 } & HBL_01 & HBL_01A & \multicolumn{2}{|c|}{ HBL_10 } & HBL_10A \\
\hline Local analisado & \multicolumn{2}{|l|}{ C } & B & C & \multicolumn{2}{|l|}{ C } & C \\
\hline $\mathrm{MnO}$ & \multicolumn{2}{|l|}{1,22} & 1,32 & 1,33 & \multicolumn{2}{|c|}{1,23} & 1,21 \\
\hline $\mathrm{MgO}$ & \multicolumn{2}{|l|}{9,20} & 9,41 & 9,23 & \multicolumn{2}{|c|}{9,49} & 9,31 \\
\hline $\mathrm{CaO}$ & \multicolumn{2}{|l|}{11,31} & 11,76 & 11,26 & \multicolumn{2}{|c|}{11,35} & 11,30 \\
\hline $\mathrm{Na}_{2} \mathrm{O}$ & \multicolumn{2}{|l|}{1,49} & 1,10 & 1,42 & \multicolumn{2}{|c|}{1,48} & 1,41 \\
\hline $\mathrm{K}_{2} \mathrm{O}$ & \multicolumn{2}{|l|}{1,98} & 1,89 & 1,99 & \multicolumn{2}{|c|}{1,93} & 2,01 \\
\hline Total (\% mas) & \multicolumn{2}{|l|}{97,36} & 97,87 & 97,60 & \multicolumn{2}{|c|}{97,95} & 97,01 \\
\hline $\mathrm{Si}$ & 6,35 & & 6,39 & 6,31 & 6,32 & & 6,31 \\
\hline $\mathrm{Al}^{\mathrm{IV}}$ & 1,65 & & 1,61 & 1,69 & 1,69 & & 1,69 \\
\hline $\mathrm{Al}^{\mathrm{VI}}$ & 0,23 & & 0,23 & 0,21 & 0,21 & & 0,23 \\
\hline $\mathrm{Ti}$ & 0,21 & & 0,22 & 0,20 & 0,20 & & 0,20 \\
\hline $\mathrm{Fe}^{3+}$ & 0,32 & & 0,36 & 0,44 & 0,43 & & 0,41 \\
\hline $\mathrm{Fe}^{2+}$ & 2,05 & & 1,95 & 1,95 & 1,93 & & 1,95 \\
\hline $\mathrm{Mg}$ & 2,10 & & 2,13 & 2,10 & 2,15 & & 2,13 \\
\hline $\mathrm{Mn}$ & 0,09 & & 0,13 & 0,10 & 0,09 & & 0,09 \\
\hline $\mathrm{Fe}^{2+}$ & 0,00 & & 0,00 & 0,00 & 0,00 & & 0,00 \\
\hline $\mathrm{Mn}$ & 0,07 & & 0,04 & 0,07 & 0,07 & & 0,07 \\
\hline $\mathrm{Ca}$ & 1,86 & & 1,91 & 1,84 & 1,85 & & 1,86 \\
\hline $\mathrm{Na}$ & 0,08 & & 0,05 & 0,09 & 0,08 & & 0,08 \\
\hline $\mathrm{Na}$ & 0,36 & & 0,28 & 0,34 & 0,36 & & 0,34 \\
\hline $\mathrm{K}$ & 0,39 & & 0,37 & 0,39 & 0,37 & & 393,00 \\
\hline Total (cat) & 15,75 & & 15,64 & 15,72 & 15,7 & & 15,74 \\
\hline 0 & 23 & & 23 & 23 & 23 & & 23 \\
\hline $\mathrm{X}_{\mathrm{Mg}}$ & 0,51 & & 0,52 & 0,52 & 0,53 & & 0,52 \\
\hline Amostras & & & & RDIT 41 & & & \\
\hline Grão & CA_HBL1 & CA_HBL2 & CA_HBL3 & CB_HBL1 & CB_HBL1 & CB_HBL2 & CB_HBL2 \\
\hline Local analisado & C & C & C & C & B & C & B \\
\hline $\mathrm{SiO}_{2}$ & 41,43 & 40,44 & 41,40 & 41,94 & 42,82 & 41,47 & 42,41 \\
\hline $\mathrm{TiO}_{2}$ & 1,55 & 1,39 & 1,44 & 1,41 & 0,82 & 1,42 & 0,84 \\
\hline $\mathrm{Al}_{2} \mathrm{O}_{3}$ & 9,95 & 9,94 & 9,93 & 10,07 & 9,64 & 10,05 & 9,74 \\
\hline $\mathrm{FeO}$ & 18,30 & 18,25 & 18,06 & 18,09 & 18,70 & 18,14 & 18,02 \\
\hline $\mathrm{MnO}$ & 1,22 & 1,16 & 1,12 & 1,11 & 1,02 & 1,07 & 1,06 \\
\hline $\mathrm{MgO}$ & 9,97 & 9,84 & 9,66 & 9,93 & 10,24 & 10,01 & 10,16 \\
\hline $\mathrm{CaO}$ & 11,19 & 11,31 & 11,06 & 11,29 & 11,62 & 11,23 & 11,44 \\
\hline $\mathrm{Na}_{2} \mathrm{O}$ & 1,75 & 1,61 & 1,84 & 1,83 & 1,37 & 1,88 & 1,40 \\
\hline $\mathrm{K}_{2} \mathrm{O}$ & 1,95 & 2,00 & 2,01 & 2,07 & 1,81 & 2,07 & 1,84 \\
\hline
\end{tabular}


Tabela 2. Continuação

\begin{tabular}{|c|c|c|c|c|c|c|c|}
\hline \multirow{2}{*}{$\begin{array}{l}\text { Amostras } \\
\text { Grão }\end{array}$} & \multicolumn{7}{|c|}{ RDIT 41} \\
\hline & CA_HBL1 & CA_HBL2 & CA_HBL3 & CB_HBL1 & CB_HBL1 & CB_HBL2 & CB_HBL2 \\
\hline Local analisado & C & C & C & C & B & C & B \\
\hline Total (\% mas) & 97,30 & 95,92 & 96,53 & 97,75 & 98,02 & 97,34 & 96,91 \\
\hline $\mathrm{Si}$ & 6,34 & 6,28 & 6,40 & 6,40 & 6,46 & 6,35 & 6,47 \\
\hline $\mathrm{Al}^{\mathrm{IV}}$ & 1,66 & 1,72 & 1,60 & 1,61 & 1,54 & 1,65 & 1,53 \\
\hline $\mathrm{Al}^{\mathrm{VI}}$ & 0,13 & 0,10 & 0,21 & 0,20 & 0,17 & 0,16 & 0,22 \\
\hline $\mathrm{Ti}$ & 0,18 & 0,16 & 0,17 & 0,16 & 0,09 & 0,16 & 0,10 \\
\hline $\mathrm{Fe}^{3+}$ & 0,46 & 0,55 & 0,29 & 0,30 & 0,56 & 0,36 & 0,48 \\
\hline $\mathrm{Fe}^{2+}$ & 1,88 & 1,82 & 2,04 & 2,01 & 1,80 & 1,96 & 1,82 \\
\hline $\mathrm{Mg}$ & 2,27 & 2,28 & 2,23 & 2,26 & 2,30 & 2,28 & 2,31 \\
\hline $\mathrm{Mn}$ & 0,08 & 0,10 & 0,07 & 0,07 & 0,07 & 0,07 & 0,08 \\
\hline $\mathrm{Fe}^{2+}$ & 0,00 & 0,00 & 0,01 & 0,00 & 0,00 & 0,00 & 0,00 \\
\hline $\mathrm{Mn}$ & 0,08 & 0,06 & 0,07 & 0,07 & 0,06 & 0,07 & 0,06 \\
\hline $\mathrm{Ca}$ & 1,83 & 1,88 & 1,83 & 1,85 & 1,88 & 1,84 & 1,87 \\
\hline $\mathrm{Na}$ & 0,09 & 0,06 & 0,09 & 0,08 & 0,07 & 0,08 & 0,07 \\
\hline $\mathrm{Na}$ & 0,43 & 0,42 & 0,46 & 0,46 & 0,34 & 0,47 & 0,35 \\
\hline $\mathrm{K}$ & 0,38 & 0,40 & 0,40 & 0,40 & 0,35 & 0,40 & 0,36 \\
\hline Total (cat) & 15,81 & 15,82 & 15,86 & 15,86 & 15,68 & 15,88 & 15,70 \\
\hline 0 & 23 & 23 & 23 & 23 & 23 & 23 & 23 \\
\hline $\mathrm{X}_{\mathrm{Mg}}$ & 0,55 & 0,56 & 0,52 & 0,53 & 0,56 & 0,54 & 0,56 \\
\hline \multicolumn{4}{|l|}{ Amostras } & \multicolumn{3}{|l|}{ RDIT 41} & \\
\hline Grão & CC_HBL1 & CC_HBL2 & CC_HBL2 & CE_HBL1 & $\begin{array}{c}\text { CE_(ACT) } \\
\text { HBL1 }\end{array}$ & CE_HBL2 & $\begin{array}{c}\text { CE_(ACT) } \\
\text { HBL2 }\end{array}$ \\
\hline Local analisado & B & C & B & C & C & $\mathrm{C}$ & C \\
\hline $\mathrm{SiO}_{2}$ & 40,51 & 41,77 & 41,58 & 42,87 & 40,37 & 41,70 & 41,05 \\
\hline $\mathrm{TiO}_{2}$ & 0,82 & 1,33 & 0,85 & 1,33 & 1,26 & 1,24 & 0,94 \\
\hline $\mathrm{Al}_{2} \mathrm{O}_{3}$ & 11,08 & 10,02 & 10,56 & 9,59 & 9,99 & 9,76 & 10,23 \\
\hline $\mathrm{FeO}$ & 19,34 & 17,93 & 18,94 & 17,50 & 17,71 & 17,88 & 18,61 \\
\hline $\mathrm{MnO}$ & 1,04 & 1,05 & 0,32 & 1,12 & 1,18 & 1,13 & 1,17 \\
\hline $\mathrm{MgO}$ & 9,53 & 10,03 & 9,55 & 10,12 & 9,87 & 9,96 & 9,20 \\
\hline $\mathrm{CaO}$ & 11,27 & 11,33 & 11,40 & 11,29 & 11,40 & 11,34 & 11,55 \\
\hline $\mathrm{Na}_{2} \mathrm{O}$ & 1,53 & 1,86 & 1,39 & 1,57 & 1,49 & 1,62 & 1,38 \\
\hline $\mathrm{K}_{2} \mathrm{O}$ & 2,13 & 2,01 & 2,01 & 1,94 & 2,00 & 1,95 & 1,85 \\
\hline Total (\% mas) & 97,23 & 973,26 & 96,59 & 97,35 & 95,27 & 96,58 & 95,99 \\
\hline $\mathrm{Si}$ & 6,20 & 6,39 & 6,39 & 6,53 & 6,30 & 6,42 & 6,37 \\
\hline $\mathrm{Al}^{\mathrm{IV}}$ & 1,80 & 1,61 & 1,61 & 1,47 & 1,70 & 1,58 & 1,63 \\
\hline $\mathrm{Al}^{\mathrm{VI}}$ & 0,19 & 0,20 & 0,30 & 0,25 & 0,13 & 0,19 & 0,23 \\
\hline $\mathrm{Ti}$ & 0,10 & 0,15 & 0,10 & 0,15 & 0,15 & 0,14 & 0,11 \\
\hline
\end{tabular}


Tabela 2. Continuação

\begin{tabular}{|c|c|c|c|c|c|c|c|}
\hline Amostras & & & & RDIT 41 & & & \\
\hline Grão & CC_HBL1 & CC_HBL2 & CC_HBL2 & CE_HBL1 & $\begin{array}{c}\text { CE_(ACT) } \\
\text { HBL1 }\end{array}$ & CE_HBL2 & $\begin{array}{c}\text { CE_(ACT) } \\
\text { HBL2 }\end{array}$ \\
\hline Local analisado & B & C & B & C & C & C & C \\
\hline $\mathrm{Fe}^{3+}$ & 0,71 & 0,31 & 0,44 & 0,25 & 0,53 & 0,39 & 0,49 \\
\hline $\mathrm{Fe}^{2+}$ & 1,76 & 1,98 & 1,95 & 1,98 & 1,79 & 1,91 & 1,93 \\
\hline $\mathrm{Mg}$ & 2,17 & 2,29 & 2,19 & 2,30 & 2,30 & 2,29 & 2,13 \\
\hline $\mathrm{Mn}$ & 0,07 & 0,07 & 0,02 & 0,07 & 0,11 & 0,09 & 0,12 \\
\hline $\mathrm{Fe}^{2+}$ & 0,00 & 0,00 & 0,04 & 0,00 & 0,00 & 0,00 & 0,00 \\
\hline $\mathrm{Mn}$ & 0,07 & 0,07 & 0,02 & 0,07 & 0,04 & 0,06 & 0,04 \\
\hline $\mathrm{Ca}$ & 1,85 & 1,86 & 1,88 & 1,84 & 1,91 & 1,87 & 1,92 \\
\hline $\mathrm{Na}$ & 0,08 & 0,08 & 0,07 & 0,08 & 0,05 & 0,07 & 0,04 \\
\hline $\mathrm{Na}$ & 0,37 & 0,48 & 0,35 & 0,38 & 0,40 & 0,41 & 0,37 \\
\hline K & 0,42 & 0,39 & 0,40 & 0,38 & 0,40 & 0,38 & 0,37 \\
\hline Total (cat) & 15,79 & 15,87 & 15,74 & 15,76 & 15,80 & 15,80 & 15,74 \\
\hline 0 & 23 & 23 & 23 & 23 & 23 & 23 & 23 \\
\hline $\mathrm{X}_{\mathrm{Mg}}$ & 0,55 & 0,54 & 0,53 & 0,54 & 0,56 & 0,54 & 0,52 \\
\hline
\end{tabular}

C: centro do grão; B: borda do grão.

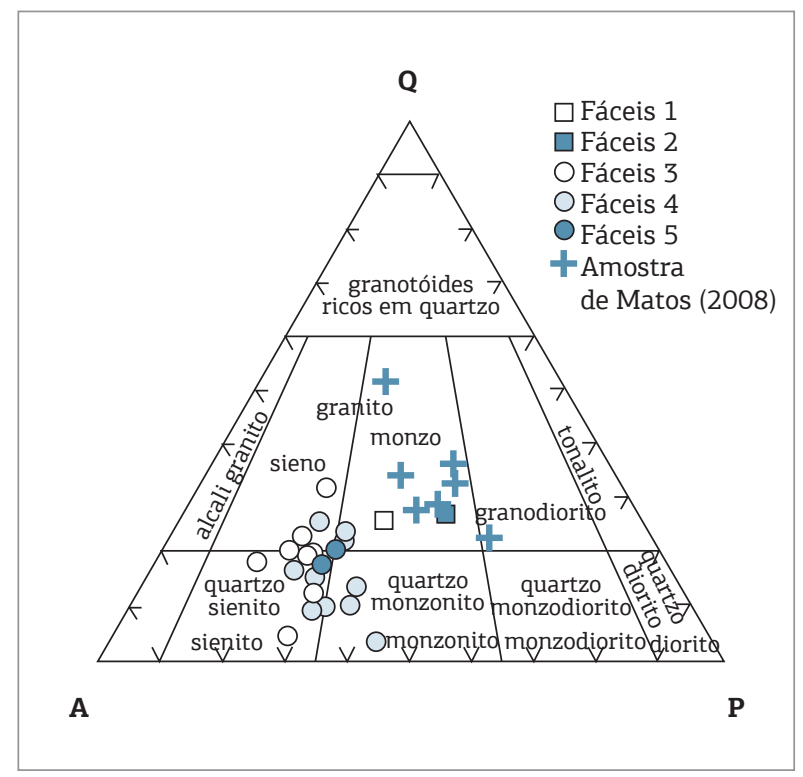

Figura 4. Diagrama QAP (Streckeisen, 1976) para as rochas do Batólito Serra da Água Limpa.

nas três amostras escolhidas (RDPA 75, VAC 11 e RDIT 41 - Tabs. 2 a 5).

Os cristais de anfibólio foram classificados segundo Leake (1997) como predominantemente magnésio hastingsita, com tendência a edenita e hastingsita (Fig. 6). Nas lâminas, além de predominantes cristais com cor natural verde musgo, vários grãos são verde azulados, possuindo aspecto anédrico, contatos irregulares e intercrescidos com quartzo. Uma mudança composicional do centro para a borda ocorre em cristais verde azulados das três amostras analisadas. Essa mudança consiste no enriquecimento das bordas em $\mathrm{SiO}_{2}, \mathrm{MgO}$ e $\mathrm{CaO}$ com diminuição de $\mathrm{Al}_{2} \mathrm{O}_{3}$, $\mathrm{FeO}, \mathrm{Na}_{2} \mathrm{O}$ e $\mathrm{K}_{2} \mathrm{O}$ (Tab. 2). Essa modificação composicional é responsável pela coloração verde azulada observada nas bordas dos cristais de hornblenda (Fig. 7), já que essa coloração está vinculada à concentração de Mg (Fig. 8 e Tab. 2). Tais modificaçôes nas bordas dos cristais podem estar relacionadas ao metamorfismo, uma vez que essa coloração verde azulada é muito comum em anfibólios metamórficos. Além disso, são comuns cristais de hornblenda substituídos por biotita nos domínios de borda. Por vezes essa biotita está em intercrescimento simplectítico com quartzo, revelando textura de provável origem metamórfica (Fig. 9).

O plagioclásio, andesina e oligoclásio (Fig. 10), também apresentou nas três amostras analisadas uma modificação em seus domínios de borda, dada principalmente pelo aumento nas concentraçóes de $\mathrm{Na}_{2} \mathrm{O}$ e redução nos teores de $\mathrm{CaO}$ (Tab. 3). 

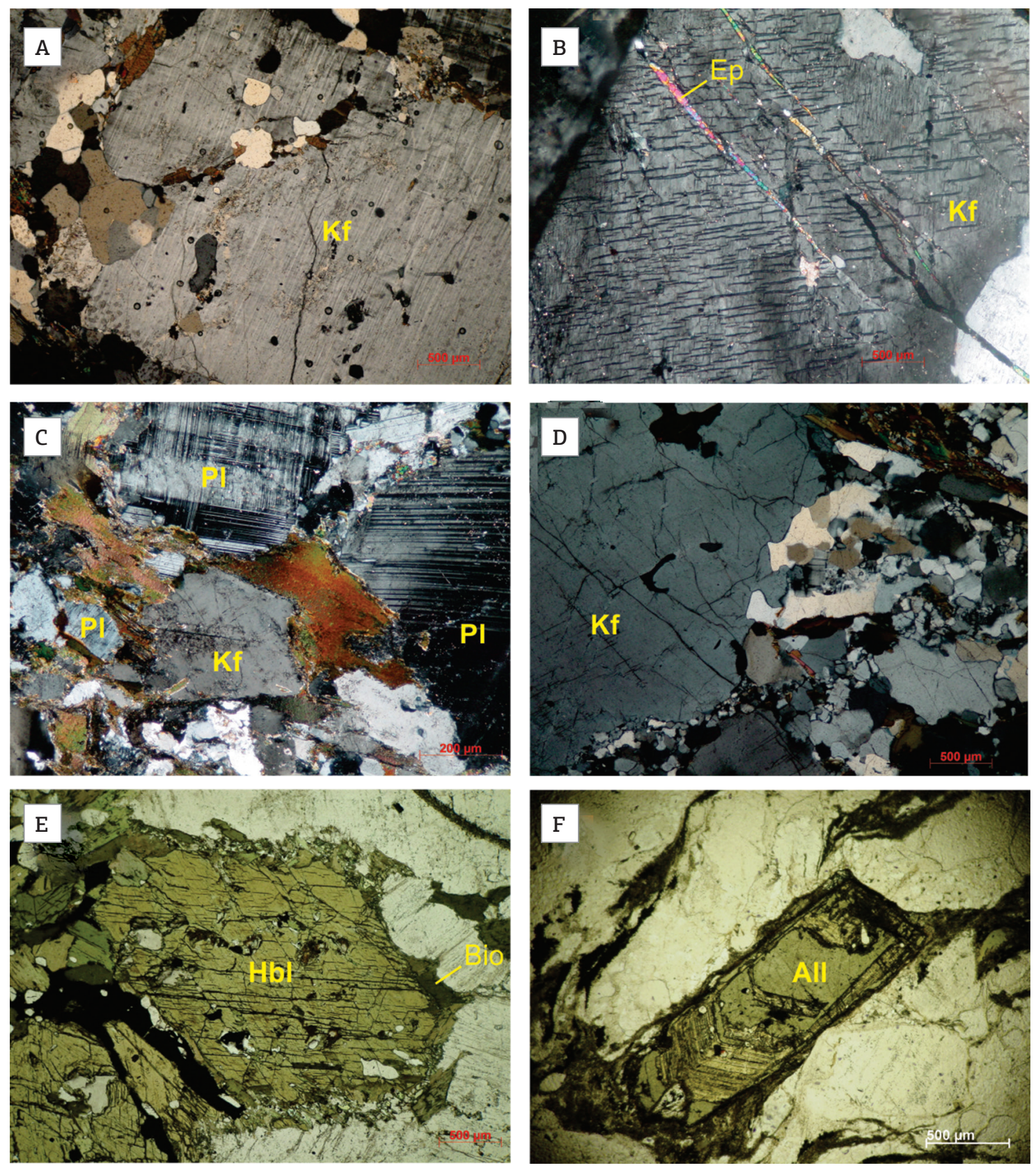

Kf: K-feldspato; Ep: epidoto; Pl: plagioclásio; Hbl: hornblenda; Bio: biotita; All: allanita.

Figura 5. (A) Fenocristal de microclina, Fácies 1 do Batólito Serra da Água Limpa; (B) Fenocristal de K-feldspato pertítico com epidoto ao longo de fraturas, Fácies 3 do Batólito Serra da Água Limpa; (C) Predomínio de plagioclásio na matriz em relação a K-feldspato, Fácies 3 do Batólito Serra da Água Limpa; (D) Fenocristal de K-feldspato, cristais de quartzo recuperados em subgrãos e recristalizados, evidenciando deformação tectônica, Fácies 5 do Batólito Serra da Água Limpa; (E) Hornblenda alterando para biotita, fases máficas comuns nas rochas da Fácies 4 do Batólito Serra da Água Limpa; (F) Allanita com sobrecrescimento magmático em rocha da Fácies 4 do Batólito Serra da Água Limpa.

Uma possível explicação para a variação da composição química do centro para a borda em hornblenda e plagioclásio seria um reequilíbrio metamórfico, mas não se pode descartar a hipótese de que tal mudança composicional seja um reflexo da cristalização dessas fases minerais. 
Tabela 3. Composições químicas de plagioclásio para três amostras de rochas do Batólito Serra da Água Limpa (RDPA 75, VAC 11 e RDIT 41), totalizando 13 cristais, onde C representa a porção mais central dos grãos e B os domínios de borda

\begin{tabular}{|c|c|c|c|c|c|}
\hline \multirow{2}{*}{$\begin{array}{l}\text { Amostra } \\
\text { Grão }\end{array}$} & \multicolumn{5}{|c|}{ RDPA 75} \\
\hline & CA_PLAG & CA_PLAG & CA_PLA_A & CB_PLAG & CD_PLAG \\
\hline Local analisado & C & B & C & C & C \\
\hline $\mathrm{SiO}_{2}$ & 61,66 & 62,76 & 62,60 & 63,27 & 62,42 \\
\hline $\mathrm{Al}_{2} \mathrm{O}_{3}$ & 23,00 & 23,35 & 23,38 & 23,50 & 23,43 \\
\hline $\mathrm{FeO}$ & 0,16 & 0,00 & 0,06 & 0,04 & 0,12 \\
\hline $\mathrm{CaO}$ & 5,93 & 5,78 & 5,92 & 5,62 & 5,83 \\
\hline $\mathrm{Na}_{2} \mathrm{O}$ & 8,04 & 8,74 & 8,34 & 8,41 & 8,63 \\
\hline $\mathrm{K}_{2} \mathrm{O}$ & 0,78 & 0,11 & 0,17 & 0,13 & 0,14 \\
\hline Total (\% mas) & 99,56 & 100,75 & 100,45 & 100,97 & 100,56 \\
\hline $\mathrm{Si}$ & 11,04 & 11,06 & 11,06 & 11,10 & 11,03 \\
\hline $\mathrm{Al}$ & 4,85 & 4,85 & 4,87 & 4,86 & 4,88 \\
\hline $\mathrm{Fe}^{2+}$ & 0,02 & 0,00 & 0,01 & 0,01 & 0,02 \\
\hline $\mathrm{Ca}$ & 1,14 & 1,09 & 1,12 & 1,06 & 1,10 \\
\hline $\mathrm{Na}$ & 2,79 & 2,99 & 2,86 & 2,86 & 2,96 \\
\hline K & 0,18 & 0,03 & 0,04 & 0,03 & 0,03 \\
\hline Total (cat) & 20,02 & 20,01 & 19,95 & 19,91 & 19,03 \\
\hline 0 & 32 & 32 & 32 & 32 & 32 \\
\hline $\mathrm{X}$ & 15,89 & 15,91 & 15,93 & 15,96 & 15,91 \\
\hline Z & 4,13 & 4,10 & 4,02 & 3,95 & 4,11 \\
\hline $\mathrm{Ab}$ & 68,00 & 72,80 & 71,20 & 72,50 & 72,30 \\
\hline An & 27,70 & 26,60 & 27,90 & 26,70 & 27,00 \\
\hline Or & 4,30 & 0,60 & 0,90 & 0,80 & 0,80 \\
\hline \multicolumn{3}{|l|}{ Amostra } & \multicolumn{2}{|l|}{ VAC 11} & \\
\hline Grão & Plag_08 & Plag_08 & Plag_08A & Plag_13 & Plag_13A \\
\hline Local analisado & C & B & C & C & C \\
\hline $\mathrm{SiO}_{2}$ & 61,23 & 61,29 & 60,31 & 61,76 & 61,13 \\
\hline $\mathrm{Al}_{2} \mathrm{O}_{3}$ & 24,33 & 24,07 & 24,77 & 24,42 & 24,32 \\
\hline $\mathrm{FeO}$ & - & 0,02 & - & - & - \\
\hline $\mathrm{CaO}$ & 6,72 & 6,65 & 6,93 & 6,88 & 6,94 \\
\hline $\mathrm{Na}_{2} \mathrm{O}$ & 7,79 & 8,15 & 8,05 & 7,75 & 7,39 \\
\hline $\mathrm{K}_{2} \mathrm{O}$ & - & 0,21 & - & - & - \\
\hline Total (\% mas) & 100,07 & 100,38 & 100,06 & 100,80 & 99,79 \\
\hline $\mathrm{Si}$ & 10,87 & 10,88 & 10,74 & 10,88 & 10,88 \\
\hline $\mathrm{Al}$ & 5,09 & 5,03 & 5,20 & 5,07 & 5,10 \\
\hline $\mathrm{Fe}^{2+}$ & - & 0,00 & - & - & - \\
\hline
\end{tabular}


Rodrigo Vinagre et al.

Tabela 3. Continuação

\begin{tabular}{|c|c|c|c|c|c|c|c|}
\hline \multirow{2}{*}{$\begin{array}{l}\text { Amostra } \\
\text { Grão }\end{array}$} & \multicolumn{7}{|c|}{ VAC 11} \\
\hline & \multicolumn{2}{|l|}{ Plag_08 } & Plag_08 & Plag_08A & \multicolumn{2}{|c|}{ Plag_13 } & Plag_13A \\
\hline Local analisado & C & \multicolumn{2}{|c|}{ B } & C & \multicolumn{2}{|c|}{ C } & C \\
\hline $\mathrm{Ca}$ & 1,28 & \multicolumn{2}{|c|}{1,26} & 1,32 & \multicolumn{2}{|c|}{1,30} & 1,32 \\
\hline $\mathrm{Na}$ & 2,68 & \multicolumn{2}{|c|}{2,80} & 2,78 & \multicolumn{2}{|c|}{2,68} & 2,55 \\
\hline $\mathrm{K}$ & - & \multicolumn{2}{|c|}{0,05} & - & \multicolumn{2}{|c|}{-} & - \\
\hline Total (cat) & 19,92 & \multicolumn{2}{|c|}{20,03} & 20,04 & \multicolumn{2}{|c|}{19,90} & 19,84 \\
\hline $\mathrm{O}$ & 32 & \multicolumn{2}{|c|}{32} & 32 & \multicolumn{2}{|c|}{32} & 32 \\
\hline $\mathrm{X}$ & 15,96 & \multicolumn{2}{|c|}{15,91} & 15,94 & \multicolumn{2}{|c|}{15,95} & 15,97 \\
\hline Z & 3,96 & \multicolumn{2}{|c|}{4,12} & 4,10 & \multicolumn{2}{|c|}{3,95} & 3,87 \\
\hline $\mathrm{Ab}$ & 67,70 & \multicolumn{2}{|c|}{68,10} & 67,80 & \multicolumn{2}{|c|}{67,10} & 65,80 \\
\hline An & 32,30 & \multicolumn{2}{|c|}{30,70} & 32,20 & \multicolumn{2}{|c|}{32,90} & 34,20 \\
\hline Or & 0,00 & \multicolumn{2}{|c|}{1,10} & 0,00 & & & 0,00 \\
\hline Amostra & & & & RDIT 41 & & & \\
\hline Grão & CD_PLAG1 & CD_PLAG1 & CF_PLAG1 & CF_PLAG1 & $\frac{\mathrm{CB}_{-}}{\text {PLAG_A }}$ & $\stackrel{\text { CB_- }}{\text { PLAG_B }}$ & CB_PLAG_C \\
\hline Local analisado & C & B & C & B & C & C & C \\
\hline $\mathrm{SiO}_{2}$ & 63,41 & 63,93 & 63,58 & 63,63 & 63,63 & 63,25 & 63,15 \\
\hline $\mathrm{Al}_{2} \mathrm{O}_{3}$ & 23,51 & 23,15 & 22,49 & 22,44 & 22,85 & 22,71 & 22,93 \\
\hline $\mathrm{FeO}$ & 0,04 & 0,06 & 0,09 & 0,06 & 0,11 & 0,06 & 0,04 \\
\hline $\mathrm{CaO}$ & 5,73 & 5,12 & 4,95 & 5,27 & 5,24 & 5,21 & 5,18 \\
\hline $\mathrm{Na}_{2} \mathrm{O}$ & 7,60 & 8,04 & 9,11 & 8,97 & 8,36 & 9,20 & 8,71 \\
\hline $\mathrm{K}_{2} \mathrm{O}$ & 0,22 & 0,19 & 0,36 & 0,21 & 0,21 & 0,22 & 0,22 \\
\hline Total (\% mas) & 100,51 & 100,49 & 100,59 & 100,58 & 100,40 & 100,65 & 100,23 \\
\hline $\mathrm{Si}$ & 11,14 & 11,23 & 11,22 & 11,22 & 11,21 & 11,16 & 11,16 \\
\hline $\mathrm{Al}$ & 4,87 & 4,79 & 4,67 & 4,66 & 4,74 & 4,72 & 4,77 \\
\hline $\mathrm{Fe}^{2+}$ & 0,01 & 0,01 & 0,01 & 0,01 & 0,02 & 0,01 & 0,01 \\
\hline $\mathrm{Ca}$ & 1,08 & 0,96 & 0,94 & 1,00 & 0,99 & 0,98 & 0,98 \\
\hline $\mathrm{Na}$ & 2,59 & 2,74 & 3,12 & 3,07 & 2,86 & 3,15 & 2,99 \\
\hline $\mathrm{K}$ & 0,05 & 0,04 & 0,08 & 0,05 & 0,05 & 0,05 & 0,05 \\
\hline Total (cat) & 19,73 & 19,76 & 20,04 & 20,00 & 19,86 & 20,07 & 19,96 \\
\hline 0 & 32 & 32 & 32 & 32 & 32 & 32 & 32 \\
\hline $\mathrm{X}$ & 16,01 & 16,01 & 15,89 & 15,88 & 15,95 & 15,88 & 15,94 \\
\hline Z & 3,72 & 3,75 & 4,15 & 4,12 & 3,91 & 4,19 & 4,02 \\
\hline $\mathrm{Ab}$ & 69,70 & 73,10 & 75,40 & 74,60 & 73,40 & 75,30 & 74,30 \\
\hline An & 29,00 & 25,80 & 22,60 & 24,20 & 25,40 & 23,50 & 24,40 \\
\hline Or & 1,30 & 1,10 & 2,00 & 1,20 & 1,20 & 1,20 & 1,20 \\
\hline
\end{tabular}

C: centro do grão; B: borda do grão. 
Tabela 4. Composições químicas de biotita para três amostras de rochas do Batólito Serra da Água Limpa (RDPA 75, VAC 11 e RDIT 41), totalizando 14 cristais, onde $C$ representa a porção mais central dos grãos

\begin{tabular}{|c|c|c|c|c|c|}
\hline \multirow{2}{*}{$\begin{array}{l}\text { Amostras } \\
\text { Grão }\end{array}$} & \multicolumn{5}{|c|}{ RDPA 75} \\
\hline & CD_BIOT & CA_BIOT_D & CA_BIOT_C & CA_BIOT_A & CA_BIOT_B \\
\hline Local analisado & C & C & C & C & C \\
\hline $\mathrm{SiO}_{2}$ & 38,70 & 38,61 & 38,09 & 38,75 & 38,88 \\
\hline $\mathrm{TiO}_{2}$ & 1,57 & 1,76 & 4,02 & 2,52 & 2,06 \\
\hline $\mathrm{Al}_{2} \mathrm{O}_{3}$ & 14,74 & 15,26 & 14,69 & 14,97 & 15,31 \\
\hline $\mathrm{FeO}$ & 16,69 & 17,06 & 15,84 & 16,41 & 17,00 \\
\hline $\mathrm{MgO}$ & 15,33 & 14,49 & 13,10 & 13,86 & 13,62 \\
\hline $\mathrm{K}_{2} \mathrm{O}$ & 10,03 & 10,06 & 9,70 & 9,93 & 10,12 \\
\hline Total (\% mas) & 97,07 & 97,24 & 95,45 & 96,43 & 97,00 \\
\hline $\mathrm{Si}$ & 5,76 & 5,76 & 5,85 & 5,86 & 5,85 \\
\hline $\mathrm{Al}^{\mathrm{IV}}$ & 2,24 & 2,24 & 2,15 & 2,15 & 2,15 \\
\hline $\mathrm{Al}^{\mathrm{VI}}$ & 0,35 & 0,45 & 0,50 & 0,52 & 0,57 \\
\hline $\mathrm{Ti}$ & 0,18 & 0,20 & 0,47 & 0,29 & 0,23 \\
\hline $\mathrm{Fe}^{2+}$ & 2,08 & 2,13 & 2,03 & 2,07 & 2,14 \\
\hline $\mathrm{Mg}$ & 3,40 & 3,22 & 3,00 & 3,12 & 3,06 \\
\hline K & 1,91 & 1,92 & 1,90 & 1,91 & 1,94 \\
\hline Total (cat) & 15,91 & 15,92 & 15,90 & 15,91 & 15,95 \\
\hline 0 & 24 & 24 & 24 & 24 & 24 \\
\hline Fe_FeMg & 0,38 & 0,40 & 0,40 & 0,40 & 0,41 \\
\hline Mg_FeMg & 0,62 & 0,60 & 0,60 & 0,60 & 0,59 \\
\hline \multicolumn{3}{|l|}{ Amostras } & \multicolumn{2}{|l|}{ VAC 11} & \\
\hline Grão & ВIOT02 & ВIOT02A & C8BIOT_A & C8BIOT_B & C8BIOT_C \\
\hline Local analisado & C & C & C & C & C \\
\hline $\mathrm{SiO}_{2}$ & 38,75 & 38,66 & 37,51 & 36,82 & 38,22 \\
\hline $\mathrm{TiO}_{2}$ & 2,82 & 2,84 & 2,77 & 2,52 & 2,95 \\
\hline $\mathrm{Al}_{2} \mathrm{O}_{3}$ & 15,13 & 15,41 & 15,31 & 15,67 & 15,33 \\
\hline $\mathrm{FeO}$ & 18,57 & 17,68 & 18,26 & 18,32 & 18,79 \\
\hline $\mathrm{MgO}$ & 12,11 & 12,28 & 12,16 & 11,57 & 12,19 \\
\hline $\mathrm{K}_{2} \mathrm{O}$ & 10,15 & 10,09 & 10,12 & 10,28 & 10,14 \\
\hline Total (\% mas) & 97,53 & 96,96 & 96,14 & 95,18 & 97,61 \\
\hline $\mathrm{Si}$ & 5,88 & 5,88 & 5,77 & 5,75 & 5,79 \\
\hline $\mathrm{Al}^{\mathrm{IV}}$ & 2,12 & 2,12 & 2,23 & 2,26 & 2,21 \\
\hline $\mathrm{Al}^{\mathrm{VI}}$ & 0,58 & 0,64 & 0,54 & 0,62 & 0,53 \\
\hline $\mathrm{Ti}$ & 0,32 & 0,32 & 0,32 & 0,30 & 0,34 \\
\hline $\mathrm{Fe}^{2+}$ & 2,36 & 2,25 & 2,35 & 2,39 & 2,38 \\
\hline
\end{tabular}


Tabela 4. Continuação

\begin{tabular}{|c|c|c|c|c|c|}
\hline \multirow{2}{*}{$\begin{array}{l}\text { Amostras } \\
\text { Grão }\end{array}$} & \multicolumn{5}{|c|}{ VAC 11} \\
\hline & ВIOT02 & ВIOT02A & C8BIOT_A & C8BIOT_B & C8BIOT_C \\
\hline Local analisado & C & C & C & C & C \\
\hline $\mathrm{Mg}$ & 2,74 & 2,79 & 2,79 & 2,69 & 2,75 \\
\hline K & 1,97 & 1,96 & 1,99 & 2,05 & 1,96 \\
\hline Total (cat) & 15,97 & 15,96 & 15,99 & 16,05 & 15,96 \\
\hline 0 & 24 & 24 & 24 & 24 & 24 \\
\hline $\mathrm{Fe} \_\mathrm{FeMg}$ & 0,46 & 0,45 & 0,46 & 0,47 & 0,46 \\
\hline Mg_FeMg & 0,54 & 0,55 & 0,54 & 0,53 & 0,54 \\
\hline \multicolumn{3}{|l|}{ Amostras } & \multicolumn{2}{|l|}{ RDIT 41} & \\
\hline \multicolumn{2}{|r|}{ CD_BIOT_1 } & \multicolumn{2}{|c|}{ CD_BIOT_2 } & CB_BIOT_A & CB_BIOT_B \\
\hline Local analisado & c & & & c & c \\
\hline $\mathrm{SiO}_{2}$ & 38,96 & & & 39,67 & 39,30 \\
\hline $\mathrm{TiO}_{2}$ & 2,50 & & & 2,59 & 2,49 \\
\hline $\mathrm{Al}_{2} \mathrm{O}_{3}$ & 14,34 & & & 14,12 & 14,36 \\
\hline $\mathrm{FeO}$ & 15,26 & & & 15,20 & 15,68 \\
\hline $\mathrm{MgO}$ & 14,82 & & & 15,17 & 15,33 \\
\hline $\mathrm{K}_{2} \mathrm{O}$ & 10,20 & & & 10,29 & 10,31 \\
\hline Total (\% mas) & 96,08 & & & 97,04 & 97,47 \\
\hline $\mathrm{Si}$ & 5,89 & & & 5,94 & 5,85 \\
\hline $\mathrm{Al}^{\mathrm{IV}}$ & 2,11 & & & 2,07 & 2,15 \\
\hline $\mathrm{Al}^{\mathrm{VI}}$ & 0,44 & & & 0,42 & 0,37 \\
\hline $\mathrm{Ti}$ & 0,29 & & & 0,29 & 0,28 \\
\hline $\mathrm{Fe}^{2+}$ & 1,93 & & & 1,90 & 1,95 \\
\hline $\mathrm{Mg}$ & 3,34 & & & 3,38 & 3,40 \\
\hline $\mathrm{K}$ & 1,97 & & & 1,96 & 1,96 \\
\hline Total (cat) & 15,97 & & & 15,96 & 15,96 \\
\hline 0 & 24 & & & 24 & 24 \\
\hline $\mathrm{Fe} \_\mathrm{FeMg}$ & 0,37 & & & 0,36 & 0,36 \\
\hline Mg_FeMg & 0,63 & & & 0,64 & 0,64 \\
\hline
\end{tabular}

C: centro do grão.

Quanto à biotita, é a fase que melhor define a foliação metamórfica nas rochas do BSAL. Alguns cristais de biotita ocorrem associados a anfibólio, e foram interpretados como produto de substituição metamórfica. Em muitas lâminas as relaçóes entre cristais de biotita e hornblenda sugerem pelo menos duas geraçôes de biotita, observando-se sobrecrescimento de biotita sobre biotita e sobre hornblenda. As análises químicas de biotita encontram-se na Tab. 4. Os resultados mostram variaçôes composicionais relacionadas principalmente $\mathrm{a} \mathrm{TiO}_{2}$, $\mathrm{FeO}$ e $\mathrm{MgO}$, com destaque para o $\mathrm{TiO}_{2}$. Os cristais associados a anfibólio possuem os menores valores de $\mathrm{TiO}_{2}$ e os maiores de $\mathrm{MgO}$. Quanto aos cristais isolados, verifica-se que a biotita interpretada como primária possui 
Tabela 5. Composições químicas de K-feldspato para três amostras de rochas do Batólito Serra da Água Limpa (RDPA 75, VAC 11 e RDIT 41), totalizando 14 cristais, onde F representa os fenocristais e $M$ os cristais constituintes da matriz

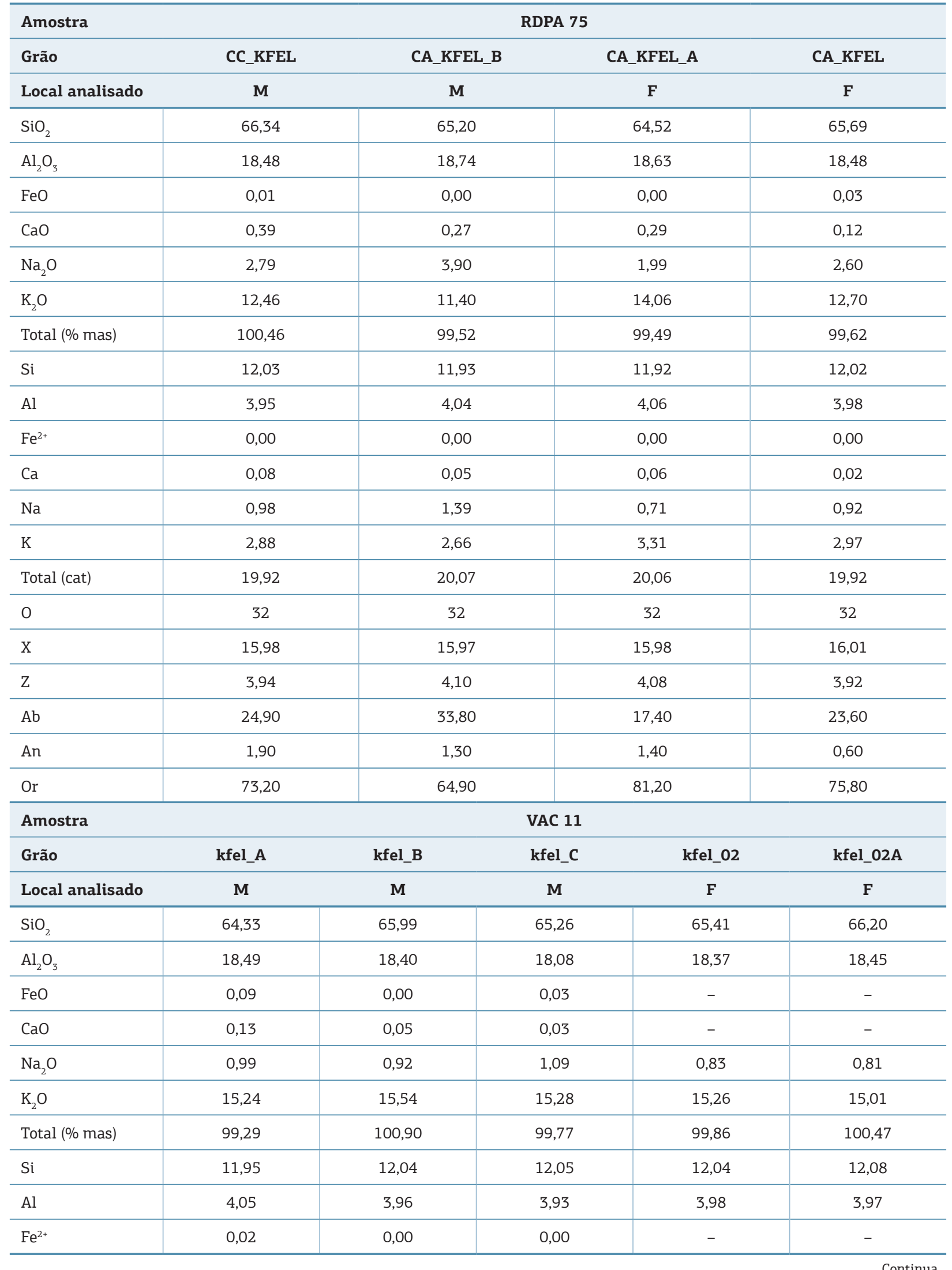


Tabela 5. Continuação

\begin{tabular}{|c|c|c|c|c|c|}
\hline \multicolumn{3}{|l|}{ Amostra } & \multicolumn{2}{|l|}{ VAC 11} & \multirow[b]{2}{*}{ kfel_02A } \\
\hline Grão & kfel_A & kfel_B & kfel_C & kfel_02 & \\
\hline Local analisado & $\mathbf{M}$ & $\mathbf{M}$ & $\mathbf{M}$ & $\mathbf{F}$ & $\mathbf{F}$ \\
\hline $\mathrm{Ca}$ & 0,03 & 0,01 & 0,01 & - & - \\
\hline $\mathrm{Na}$ & 0,36 & 0,33 & 0,39 & 0,29 & 0,29 \\
\hline $\mathrm{K}$ & 3,61 & 3,62 & 3,60 & 3,58 & 3,49 \\
\hline Total (cat) & 20,01 & 19,95 & 19,98 & 19,90 & 19,82 \\
\hline 0 & 32 & 32 & 32 & 32 & 32 \\
\hline $\mathrm{X}$ & 16,00 & 16,00 & 15,98 & 16,02 & 16,04 \\
\hline Z & 4,01 & 3,95 & 4,00 & 3,88 & 3,78 \\
\hline $\mathrm{Ab}$ & 8,90 & 8,20 & 9,80 & 7,60 & 7,50 \\
\hline An & 0,70 & 0,30 & 0,20 & 0,00 & 0,00 \\
\hline Or & 90,40 & 91,50 & 90,10 & 92,40 & 92,50 \\
\hline \multicolumn{3}{|l|}{ Amostra } & \multicolumn{2}{|l|}{ RDIT 41} & \\
\hline Grão & CB_KFEL_A & CB_KFEL_B & CB_KFEL_D & CF_KFEL1 & CB_KFEL_C \\
\hline Local analisado & $\mathbf{M}$ & $\mathbf{M}$ & $\mathbf{M}$ & $\mathbf{M}$ & $\mathbf{F}$ \\
\hline $\mathrm{SiO}_{2}$ & 64,35 & 64,30 & 64,27 & 64,17 & 64,36 \\
\hline $\mathrm{Al}_{2} \mathrm{O}_{3}$ & 18,43 & 18,26 & 18,50 & 18,57 & 18,23 \\
\hline $\mathrm{FeO}$ & 0,04 & 0,01 & 0,01 & 0,03 & 0,03 \\
\hline $\mathrm{CaO}$ & 0,04 & 0,01 & 0,07 & 0,24 & 0,08 \\
\hline $\mathrm{Na}_{2} \mathrm{O}$ & 1,09 & 1,22 & 1,56 & 1,57 & 1,28 \\
\hline $\mathrm{K}_{2} \mathrm{O}$ & 16,16 & 15,45 & 15,11 & 14,55 & 15,45 \\
\hline Total (\% mas) & 100,11 & 99,25 & 99,52 & 99,12 & 99,42 \\
\hline $\mathrm{Si}$ & 11,92 & 11,97 & 11,92 & 11,92 & 11,96 \\
\hline $\mathrm{Al}$ & 4,02 & 4,00 & 4,04 & 4,06 & 3,99 \\
\hline $\mathrm{Fe}^{2+}$ & 0,01 & 0,00 & 0,00 & 0,01 & 0,01 \\
\hline $\mathrm{Ca}$ & 0,01 & 0,00 & 0,01 & 0,05 & 0,02 \\
\hline $\mathrm{Na}$ & 0,39 & 0,44 & 0,56 & 0,57 & 0,46 \\
\hline $\mathrm{K}$ & 3,82 & 3,67 & 3,58 & 3,45 & 3,66 \\
\hline Total (cat) & 20,17 & 20,08 & 20,12 & 20,05 & 20,10 \\
\hline 0 & 32 & 32 & 32 & 32 & 32 \\
\hline $\mathrm{X}$ & 15,94 & 15,97 & 15,97 & 15,98 & 15,95 \\
\hline $\mathrm{Z}$ & 4,22 & 4,11 & 4,15 & 4,07 & 4,14 \\
\hline $\mathrm{Ab}$ & 9,30 & 10,70 & 13,50 & 13,90 & 11,10 \\
\hline An & 0,20 & 0,00 & 0,30 & 1,20 & 0,40 \\
\hline Or & 90,60 & 89,20 & 86,20 & 84,90 & 88,50 \\
\hline
\end{tabular}

F: fenocristal; M: matriz. 


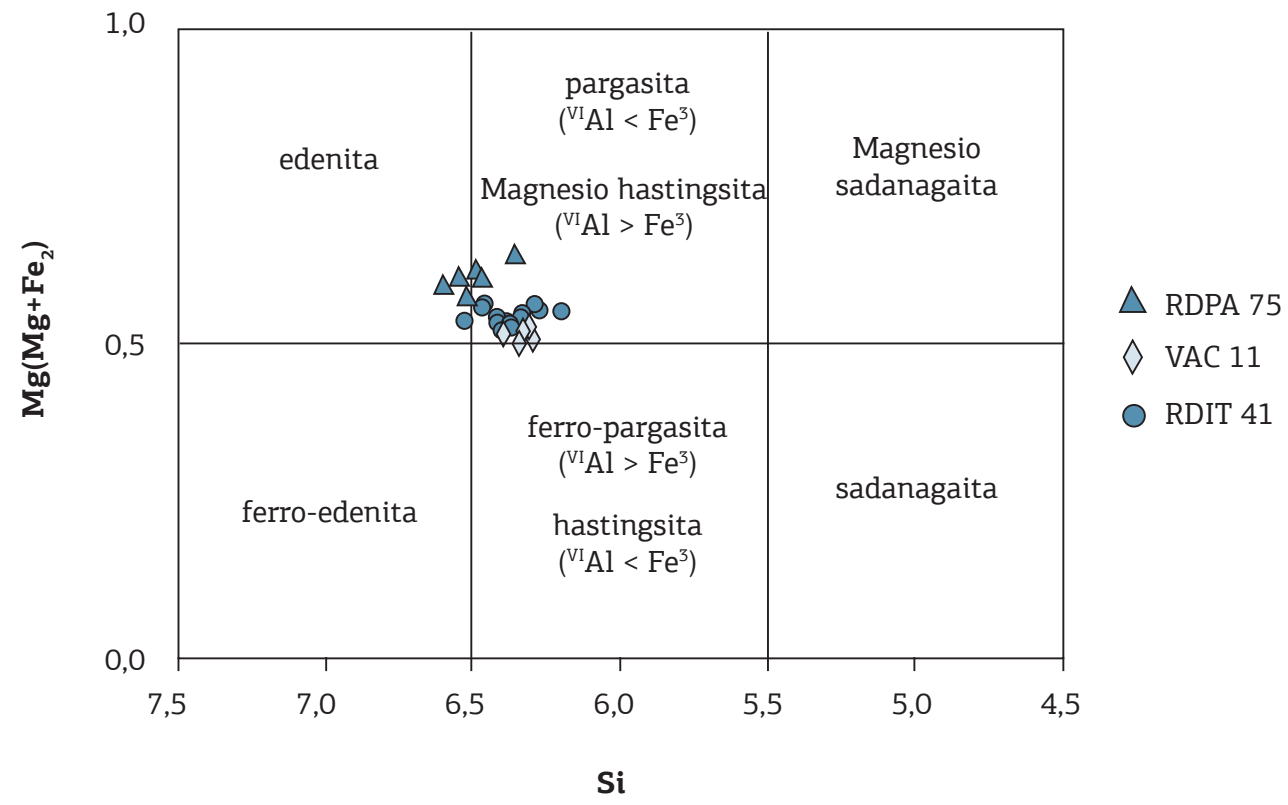

Figura 6. Classificação segundo Leake (1997) para os cristais de anfibólio analisados, mostrando que a maioria dos cristais são magnésio hastingsita com tendência a edenita e hastingsita.

um teor de $\mathrm{TiO}_{2}$ significativamente mais alto do que os demais cristais analisados, além dos mais baixos teores de $\mathrm{SiO}_{2}, \mathrm{Al}_{2} \mathrm{O}_{3}, \mathrm{FeO}, \mathrm{MgO}$ e $\mathrm{K}_{2} \mathrm{O}$. A biotita secundária tem maior quantidade de água em sua composição e os mais altos teores de $\mathrm{SiO}_{2}$.

A microclina ocorre nessas rochas tanto na forma de fenocristais quanto compondo a matriz. Por isso, foram analisados tanto fenocristais como cristais integrantes da matriz. Os resultados mostram que não há grande variação composicional entre os fenocristais e os cristais pertencentes à matriz (Tab. 5). Nota-se uma relação inversamente proporcional entre o $\mathrm{Na}_{2} \mathrm{O}$ e o $\mathrm{K}_{2} \mathrm{O}$, demonstrando a troca catiônica entre esses dois elementos, conforme se espera durante o resfriamento e cristalização de magma intermediário a ácido.

\section{Geotermobarometria}

Aqui são interpretados os equilíbrios entre as fases minerais analisadas por microssonda eletrônica, a partir das quais foram estimadas pressóes e temperaturas atuantes durante suas formaçôes. No entanto, antes disso foi utilizado o geotermômetro baseado na saturação de zircônio em rocha total.

\section{Temperatura pelo método saturação de zircônio}

Esse método, desenvolvido por Watson e Harrison (1983) e adaptado por Miller et al. (2003), é utilizado para determinar temperaturas de magmas no momento em que ocorrem as primeiras nucleaçôes de zircão, durante o alojamento de corpos ígneos na crosta. O cálculo é realizado com a porcentagem em peso de $\mathrm{Zr}$ na amostra, através da Equação 1:

$\ln \mathrm{DZr}^{\text {zircon/melt }}=(-3.80-[0.85(\mathrm{M}-1)])+12900 / \mathrm{T}$

Onde:

DZr: quantidade de zircônio na amostra;

M: relação $\left(\mathrm{Na}+\mathrm{K}+2^{*} \mathrm{Ca}\right) /(\mathrm{Al} * \mathrm{Si})$;

T: temperatura em Kelvin.

As amostras relacionadas foram as mesmas analisadas por microssonda eletrônica, RDPA 75, VAC 11 e RDIT 41, para que os valores de temperaturas obtidos por esse termômetro possam ser comparados aos adquiridos pelos métodos que utilizam química mineral.

As três amostras indicam temperaturas entre 863 e $1015^{\circ} \mathrm{C}\left(\mathrm{RDPA} 75-926^{\circ} \mathrm{C}\right.$; VAC $11-1015^{\circ} \mathrm{C}$; e RDIT $\left.41-863^{\circ} \mathrm{C}\right)$ que, segundo este método, seriam 

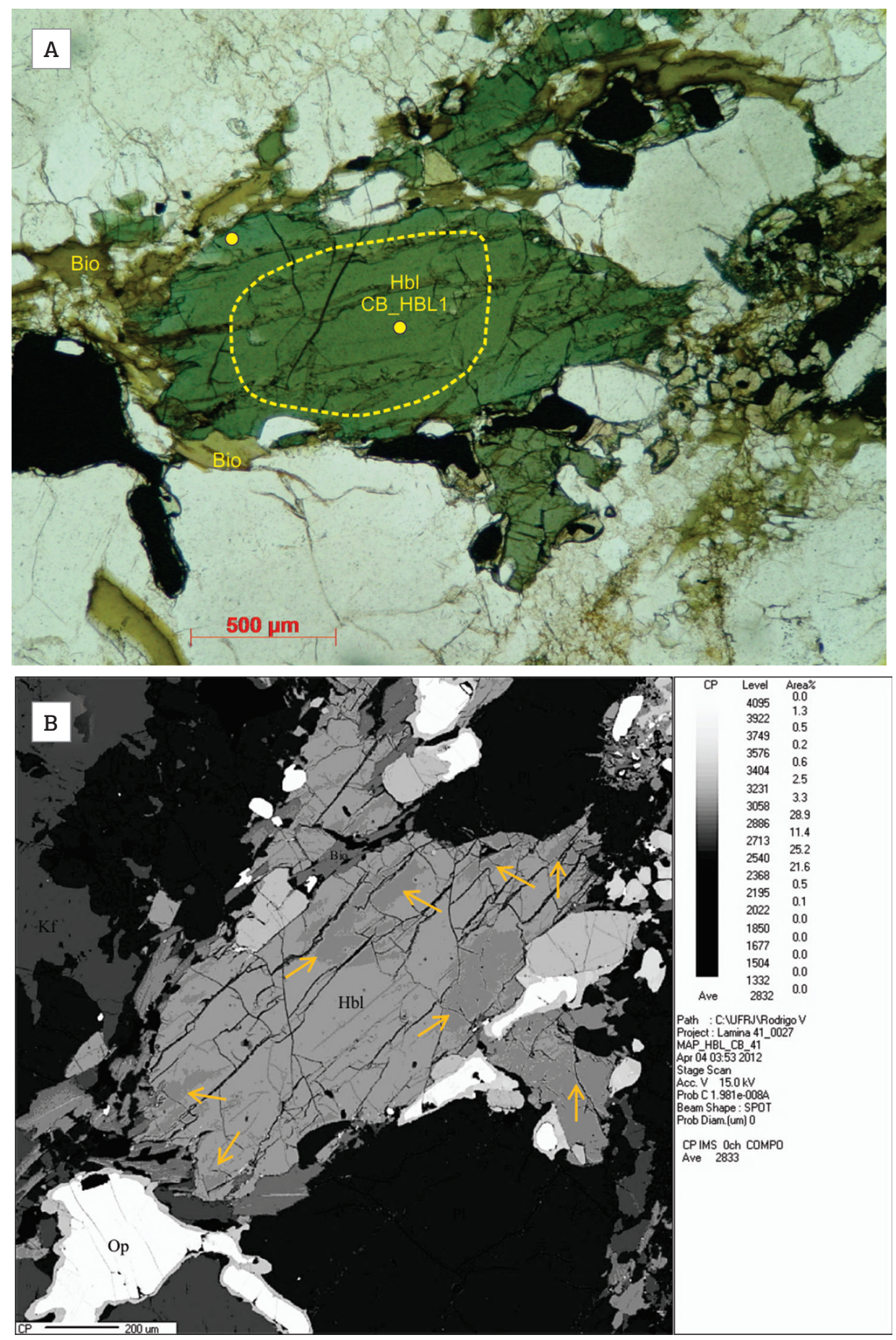

Figura 7. (A) Cristal de anfibólio CB_HBL1, escolhido para as análises composicionais em mapa, por causa da variação de cores naturais observada em lâmina delgada. A linha tracejada exalta o contraste entre as cores verde mais escuro na porção central e verde azulado nos domínios de borda do grão; (B) Imagem de elétrons retroespalhados em Microscópio Eletrônico de Varredura, onde fica claro uma séria de manchas em tom de cinza mais escuro (indicadas por setas) que coincidem com as regiões do cristal onde a cor natural verde azulado é mais intensa. 


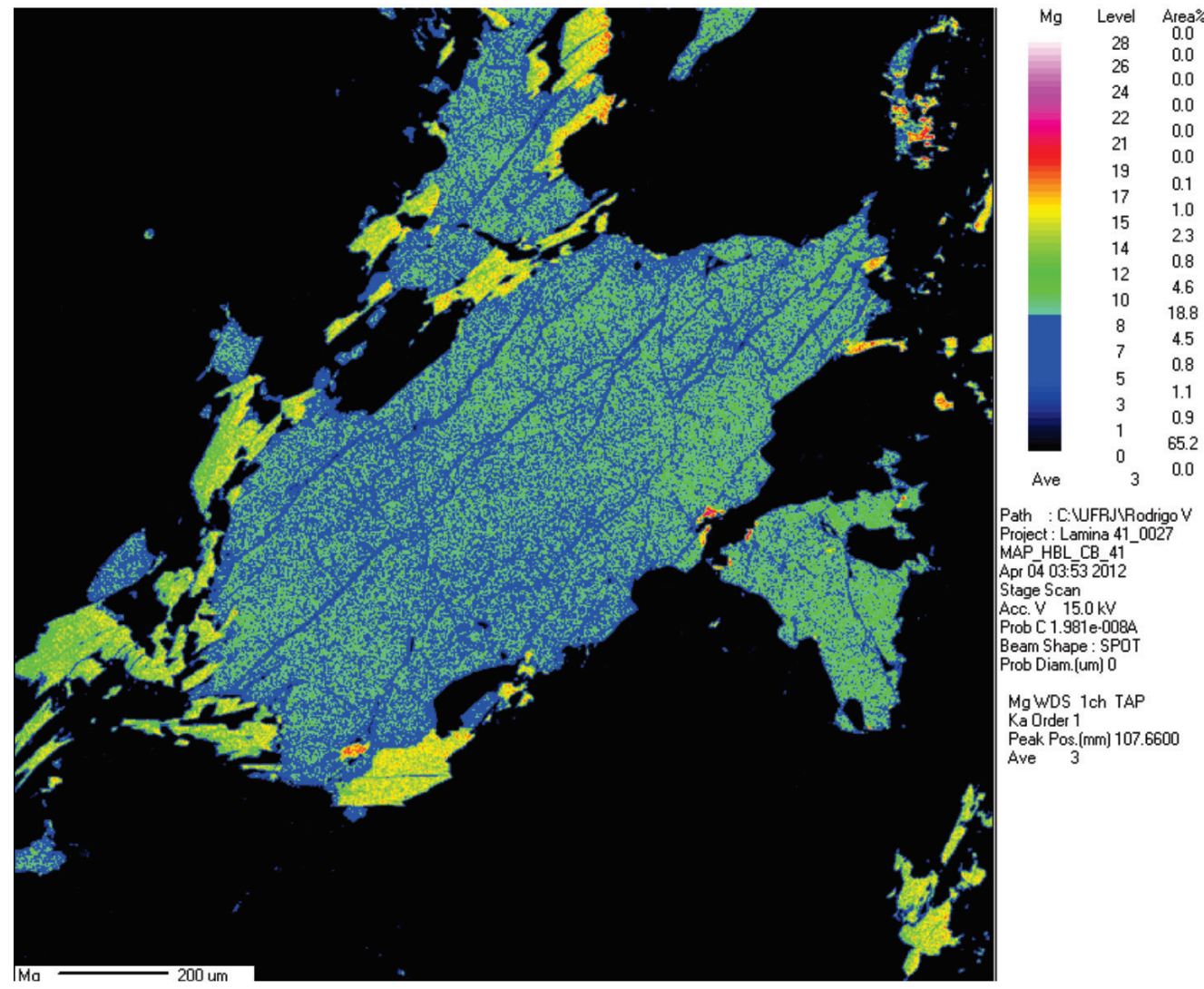

Figura 8. Mapa composicional mostrando a distribuição de Mg na hornblenda CB_HBL1 (Fig. 6A e 6B). Reparar que a porção centro-direita do cristal, assim como a borda esquerda, é significativamente mais enriquecida em $\mathrm{Mg}$.

temperaturas reinantes no início da cristalização do magma. Como nesse método não há erro estimado, acredita-se que o valor médio, em torno de $940^{\circ} \mathrm{C}$, seria uma estimativa razoável para a temperatura do magma nesse estágio da cristalização.

\section{Temperaturas e pressóes obtidas através da quimica mineral}

Foram estimadas pressões e temperaturas através de dois métodos. Um é para determinação de pressôes, proposto por Schmidt (1992), relacionado às concentraçóes de $\mathrm{Al}$ nos cristais de hornblenda, onde $\mathrm{P}$ $( \pm 0,6 \mathrm{kbar})=-3,01+4,76 \mathrm{x}$ Al total. O outro é para a obtenção de temperaturas, segundo Holland e Blundy (1994), calibrado a partir da ocorrência de hornblenda e plagioclásio junto com uma associação mineral própria de granitoides cálcio-alcalinos (i.e., K-feldspato, quartzo, titanita, biotita, óxidos de Fe e Ti). Nesse último caso, os cristais de hornblenda e plagioclásio utilizados para os cálculos são coexistentes, ocorrendo em contato uns com os outros.

As pressôes obtidas são muito similares tanto no centro como nas bordas dos cristais de hornblenda e variam entre 5 e $6 \pm 0,6$ kbar (Tab. 6).

Por sua vez, as temperaturas mostram variação conforme o local analisado nas fases minerais envolvidas ( $\mathrm{Hbl}$ e Pl). As bordas de hornblenda e plagioclásio forneceram temperaturas entre $740-770^{\circ} \mathrm{C}$ (Tab. 6) e as partes centrais proporcionaram temperaturas mais elevadas de formação, a maioria entre 830 e $860^{\circ} \mathrm{C}$ (Tab. 6). 

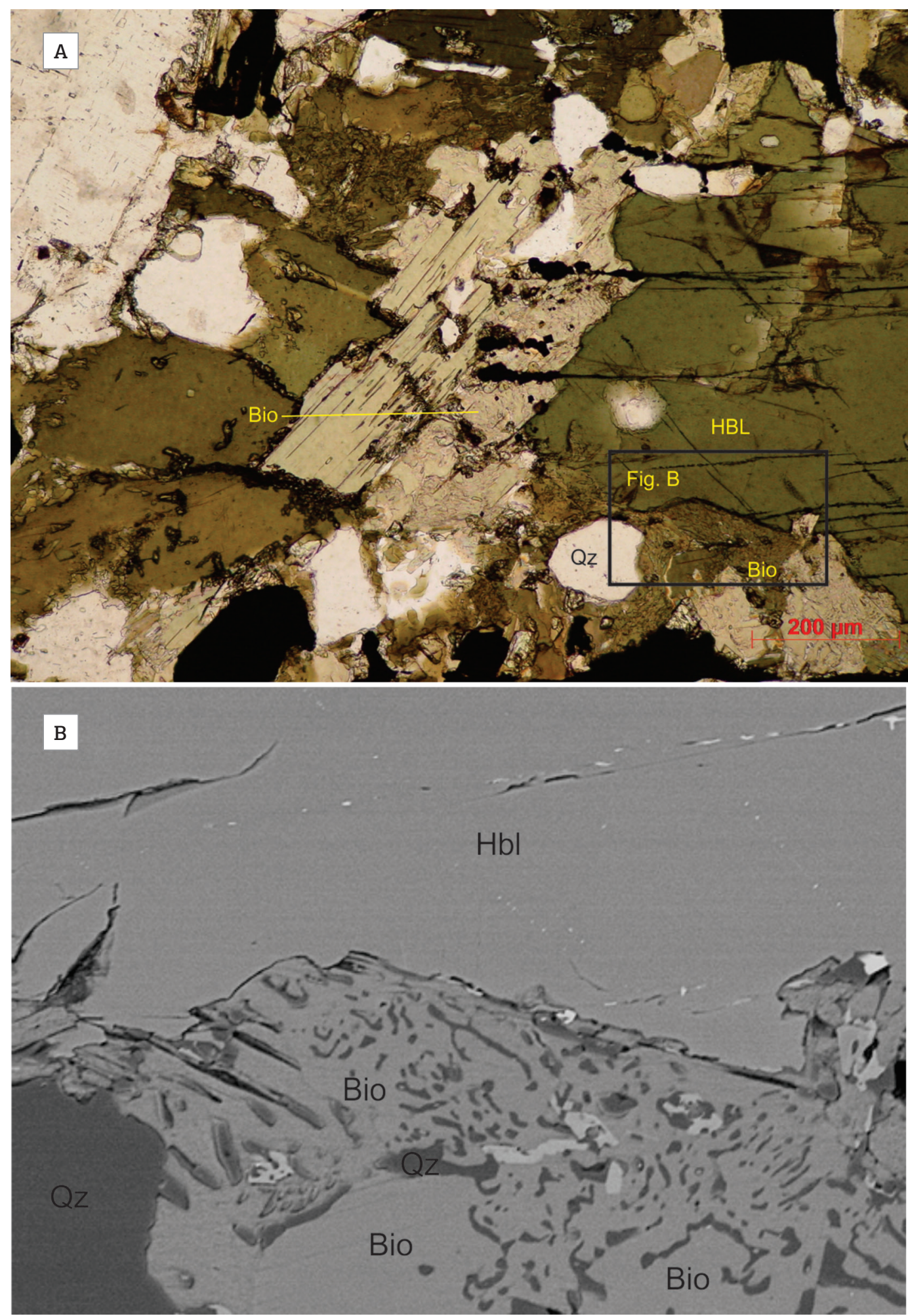

Figura 9. (A) Cristal de anfibólio substituído na borda por biotita, interpretada como produto de metamorfismo; (B) Imagem de Microscópio Eletrônico de Varredura (elétrons retroespalhados) mostrando detalhe da Fig. 8A. Fica claro o contraste entre o anfibólio e um cristal de biotita abaixo, com evidencias de intercrescimento de quartzo em vênulos (textura simplectítica), reforçando a interpretação de substituição metamórfica. 


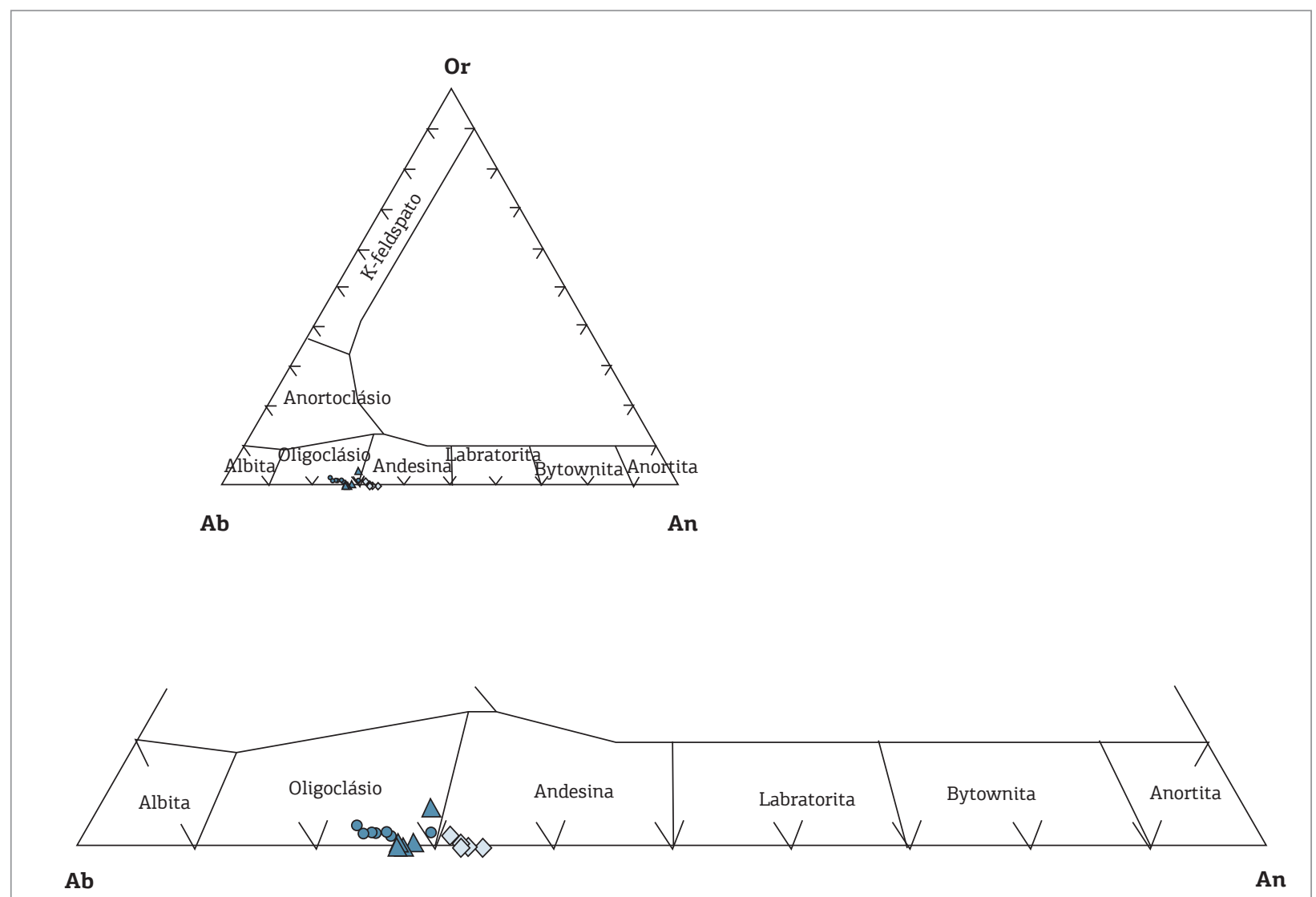

Triangulo - RDPA 75 (Batólito Serra da Água Limpa); losango - VAC 11 (Batólito Serra da Água Limpa); círculo - RDIT 41 (Batólito Serra da Água Limpa). Figura 10. Diagrama de classificação para cristais de plagioclásio do Batólito Serra da Água Limpa, mostrando que aqueles das amostras RDPA 75 e RDIT 41 plotam no campo do oligoclásio, isto é, são ligeiramente mais sódicas, enquanto que os cristais da amostra VAC 11 são andesina.

Tabela 6. Pressões e temperaturas obtidas pelos métodos de Schmidt (1992) e Holland \& Blundy (1994), respectivamente, baseadas em análises de anfibólio e plagioclásio, para amostras do Batólito Serra da Água Limpa. C representa a porção mais central do grão e B o domínio de borda

\begin{tabular}{|c|c|c|c|c|c|c|c|}
\hline \multicolumn{8}{|c|}{ Pressões e temperatura por meio de Química Mineral } \\
\hline \multirow{3}{*}{ Unidade } & \multirow{3}{*}{ Amostra } & \multirow{3}{*}{ Hornblenda } & \multirow{3}{*}{ Origem } & \multicolumn{4}{|c|}{ Método } \\
\hline & & & & \multirow{2}{*}{$\begin{array}{l}\text { Schmidt (1992) } \\
\text { Pressão (kbar) }\end{array}$} & \multicolumn{3}{|c|}{ Holland \& Blundy (1994) } \\
\hline & & & & & Plagioclásio & Origem & Temperatura ${ }^{\circ} \mathrm{C}$ \\
\hline \multirow{8}{*}{$\begin{array}{l}\text { Batólito } \\
\text { Serra } \\
\text { da Água } \\
\text { Limpa }\end{array}$} & \multirow{4}{*}{ RDPA 75} & CA_HBL (C) & ígneo? & $4,8 \pm 0,6$ & CA_PLAG(C) & ígneo? & $\sim 831$ \\
\hline & & CD_HBL (C) & ígneo? & $5,1 \pm 0,6$ & CA_PLAG(C) & ígneo? & $\sim 857$ \\
\hline & & CA_HBL_A(C) & metamórfico & $5,2 \pm 0,6$ & CA_PLAG(B) & metamórfico & $\sim 761$ \\
\hline & & CA_HBL_A(B) & metamórfico & $4,8 \pm 0,6$ & CA_PLAG(B) & metamórfico & $\sim 740$ \\
\hline & \multirow{2}{*}{ VAC 11} & HBL_01(C) & metamórfico? & $5,9 \pm 0,6$ & Plag_13A(C) & metamórfico? & $\sim 804$ \\
\hline & & HBL_01(B) & metamórfico & $5,8 \pm 0,6$ & Plag_08(B) & metamórfico & $\sim 760$ \\
\hline & \multirow{2}{*}{ RDPA 41} & CB_HBL1(C) & ígneo? & $5.6 \pm 0.6$ & CD_PLAG1(C) & ígneo? & $\sim 851$ \\
\hline & & CB_HBL1(B) & metamórfico & $5.1 \pm 0.6$ & CD_PLAG1(B) & metamórfico & $\sim 774$ \\
\hline
\end{tabular}




\section{DISCUSSÃO E CONCLUSÕES}

O BSAL é composto por rochas levemente deformadas a ortognaisses que podem ter texturas que chegam a ser miloníticas. As análises petrográficas mostraram que até nas rochas pouco deformadas, isto é, aquelas que melhor preservaram texturas magmáticas, existem evidências de recristalização metamórfica como, por exemplo, bordas de anfibólio substituído por biotita com textura simplectítica, duas geraçóes de biotita e comum recristalização do quartzo na maioria das amostras analisadas.

O entendimento ou mensuração da proporção do reequilíbrio metamórfico sofrido pelas rochas que compóem o BSAL é um desafio no estudo dessas rochas. De maneira similar, é difícil estimar se naqueles litotipos com texturas magmáticas mais preservadas, as composiçóes químicas de minerais ainda refletiriam as condiçóes da cristalização ígnea. Por esse motivo, procederam-se análises em minerais tanto da amostra RDPA 75, com textura magmática preservada, quanto naquelas muito deformadas.

No entanto, as análises de química mineral não demonstraram grandes variaçóes composicionais entres as amostras pouco e muito deformadas. O que ficou evidente é que existe uma variaçáo composicional na interface bordanúcleo dos cristais de anfibólio e plagioclásio que mostram uma redução da temperatura durante a formação da borda em relação ao núcleo dos cristais. A variação composicional na borda dos grãos pode ser resultado da cristalização magmática ou então produto de evento metamórfico posterior. Deve-se ressaltar que não há como avaliar se existem núcleos metamórficos nesses minerais, haja vista as composiçôes químicas similares de todos os núcleos analisados.

Tendo em vista o exposto acima, três hipóteses podem ser consideradas: (A) núcleos ígneos e bordas metamórficas; (B) núcleos e bordas metamórficas; e (C) núcleos e bordas ígneas.

$\mathrm{Na}$ hipótese $\mathrm{A}$, as temperaturas determinadas por meio da saturação de zircônio $\left(\sim 940^{\circ} \mathrm{C}\right)$ são interpretadas como a temperatura do magma durante o início da cristalização de zircão. Além dessas, foram determinadas duas faixas de temperaturas, uma associada às porçôes mais centrais dos cristais de plagioclásio e anfibólio (entre 830 e $860^{\circ} \mathrm{C}$ ) e outra relacionada às bordas dessas duas fases (entre 740 e $770^{\circ} \mathrm{C}$ ).

As temperaturas mais elevadas $\left(\sim 940^{\circ} \mathrm{C}\right)$ podem ser interpretadas como possíveis temperaturas próximas de liquidus, tendo a cristalização de hornblenda e plagioclásio ocorrido quando a temperatura do magma se encontrava entre 830 e $860^{\circ} \mathrm{C}$.

Como o BSAL é constituído por rochas que cristalizaram entre 670 e $630 \mathrm{Ma}$ (Vinagre et al. 2014) e assumindo a hipótese citada acima, é possível que as rochas mais velhas do BSAL, logo após cristalizarem, também foram aquecidas e metamorfisadas por conta da temperatura acumulada na crosta durante a evolução desse volumoso magmatismo, ainda na fase pré-colisional. Isso porque idades U-Pb em bordas metamórficas de zircão do batólito apontam para essa possibilidade (Vinagre et al. 2014).

As temperaturas obtidas através das bordas de anfibólio e plagioclásio, por volta de $750^{\circ} \mathrm{C}$, podem ser interpretadas como as temperaturas do auge metamórfico, transição entre as fácies anfibolito de alta temperatura e granulito, provavelmente ligado à colisão entre os paleocontinentes Paranapanema e São Francisco, que ocorreu entre 625 e $600 \mathrm{Ma}$ (Trouw 2008; Trouw et al. 2000, 2013; Duffles et al. 2013; Vinagre et al. 2014). Evidências petrográficas de modificaçóes nas bordas de anfibólio, juntamente com o crescimento de biotita segundo a foliação metamórfica principal, corroboram tal interpretação.

$\mathrm{O}$ magma que deu origem às rochas do BSAL deve ter se alojado na crosta em uma profundidade de aproximadamente $20 \mathrm{~km}$, o equivalente a 5 - 6 kbar. Esses valores de pressão são comparáveis com profundidades de corpos plutônicos em margens continentais ativas que sofreram colisão e foram erodidas até expor profundidades moderadas (Wyllie 1984; Wilson 1991). A condição de pressão durante o alojamento do batólito é muito similar à pressão registrada na posterior colisão, isso porque o corpo está alojado na placa superior (Paranapanema), onde as pressóes tendem a ser menores durante a colisão, nesse caso transição entre as fácies anfibolito de alta temperatura e pressão intermediária e granulito também de pressão intermediária.

Para a hipótese B, como já mencionado, a temperatura do magma no momento da sua colocação e início da cristalização de zircão deve ter sido em torno de $940^{\circ} \mathrm{C}$.

As duas faixas de temperatura obtidas, através de associaçôes entre núcleos (entre 830 e $860^{\circ} \mathrm{C}$ ) e bordas (entre 740 e $770^{\circ} \mathrm{C}$ ) de anfibólio e plagioclásio, poderiam ser interpretadas como produto de metamorfismo relacionado à colisão entre os paleocontinentes São Francisco e Paranapanema, levando em consideração que as composições dos cristais de anfibólio e plagioclásio presentes nas rochas do BSAL foram totalmente reequilibradas pelo metamorfismo colisional. Assim sendo, as temperaturas de cristalização das rochas do BSAL estariam acima de $860^{\circ} \mathrm{C}$, atingindo no máximo $940^{\circ} \mathrm{C}$.

$\mathrm{O}$ metamorfismo teria chegado a um ápice entre $830 \mathrm{e}$ $860^{\circ} \mathrm{C}$, fácies granulito com pressão intermediária entre 5 e $6 \mathrm{kbar}$, com retrometamorfismo em temperaturas entre 740 e $770^{\circ} \mathrm{C}$ e condiçóes idênticas de pressão, isto é, na fácies anfibolito de alta temperatura transicionando para 
granulito de pressão intermediária, no intervalo entre 625 e $600 \mathrm{Ma}$ (Trouw 2008; Trouw et al. 2000, 2013; Duffles et al. 2013; Vinagre et al. 2014). No entanto, as únicas evidências de metamorfismo fácies granulito nessa região são rochas granulíticas de protólito ígneo máfico e sedimentar (metaprecipitados químicos), que ocorrem intercaladas em gnaisses encaixantes da porção norte do BSAL. Logo, como a maior parte do corpo batolítico está encaixado em rochas com metamorfismo na fácies anfibolito, a primeira hipótese (A) parece ser a mais provável dentro desse contexto.

Para a hipótese C, pode-se considerar que a variação composicional observada nas bordas de cristais de anfibólio e plagioclásio seja produto de processos de cristalização do magma, resultando em um zoneamento núcleo-borda observado ao microscópio. No entanto, tal hipótese vai de encontro à interpretação de bordas metamórficas em cristais de zircão, com idades que coincidem com a colisão (Vinagre et al. 2014).

A primeira hipotese (A) parece a mais provavel porque é mais consistente com os dados publicados para a regiāo (Campos Neto et al. 2011; Trouw et al. 2013; Duffles et al. 2013; Vinagre et al. 2014).

\section{AGRADECIMENTOS}

Os autores são gratos aos revisores anônimos, que com suas sugestôes contribuíram significativamente com a versão final do manuscrito. Ao Conselho Nacional de Desenvolvimento Científico e Tecnológico (CNPq) pelas bolsas concedidas a R. Vinagre, R. Trouw e J. Mendes.

\section{REFERÊNCIAS}

Almeida F.F.M. 1977. O Cráton do São Francisco. Revista Brasileira de Geociências, 7(4):349-364

Almeida F.F.M. 1981. O Cráton do Paramirim e suas relações com o do São Francisco. In: SBG, Simpósio sobre o Craton do São Francisco e suas Faixas Marginais. Salvador, Anais, p. 1-10.

Basei M.A.S., Siga Júnior O., Sato K., Sproesser W.M. 1995. A metodologia urânio chumbo na Universidade de São Paulo: princípios metodológicos, aplicações e resultados obtidos. Anais Academia Brasileira de Ciências, 67(2):221-237.

Best M.G. 1982. Igneous and Metamorphic Petrology. San Francisco, W.H. Freeman and Company., 630 p.

Campos Neto, M.C. \& Caby, R. 1999. Tectonic high-pressure metamorphism and tectonic constraint from the nappe system south of São Francisco Craton, southeast Brazil. Precambrian Research, 97(1-2):3-26.

Campos Neto, M.C. \& Caby, R. 2000. Lower crust extrusion and terrane accretion in the Neoproterozoic nappes of southeast Brazil. Tectonics, 19:669-687.

Campos Neto M.C. 2000. Orogenic systems from southwestern Gondwana, an approach to Brasiliano-pan African Cycle and orogenic collage in southeastern Brazil. In: Cordani U.G., Milani E.J., Thomaz Filho A., Campos D.A. (eds.) Tectonic evolution of South America. 31st International Geological Congress. Rio de Janeiro, p. 335-365.

Campos Neto M.C., Basei M.A.S., Vlach S.R.F., Caby R., Szabó G.A.J., Vasconcelos P. 2004. Migração de orógenos e superposição de orogêneses: um esboço da colagem Brasiliana no sul do Cráton do São Francisco, SE -Brasil. Revista do Instituto de Geociências - USP, 4:13-40.

Campos Neto M.C., Basei M.A.S., Janasi V.A., Moraes R. 2011. Orogen migration and tectonic setting of the Andrelândia Nappe System: an Ediacaran western Gondwana collage, south of São Francisco Craton. Journal of South American Earth Sciences, 32(4):393-406.

Cordani U.G., Brito Neves B.B., Fuck R.A., Porto R., Thomaz Filho A., Cunha F.M.B. 1984. Estudo preliminar de integração do Pré-cambriano com os eventos tectônicos das bacias sedimentares brasileiras. Ciência, Técnica, Petróleo, Seção Exploração do Petróleo, 15:1-70.
Del Lama E.A., Zanardo A., Oliveira M.A.F., Morales N. 2000. Exhumation of high-pressure granulites of the Guaxupé Complex, southeastern Brazil. Geological Journal, 35(3-4):231-249.

Duffles P.A.T., Trouw R.A.J., Mendes J.C., Gerdes A. 2013. Marins Granite (Mg/Sp): Petrography, Geochemistry, Geochronology, and Geotectonic Setting. Brazilian Journal of Geology, 43:487-500.

Duffles P. 2013. Petrografia, geoquímica e geocronologia do Complexo Embu e rochas intrusivas associadas, folhas Lorena e Delfim Moreira (1:50.000), estados de SP e MG. Tese de Doutorado, Instituto de Geociências, Universidade Federal do Rio de Janeiro, Rio de Janeiro, 260 p.

Ebert H.D., Chemale Junior F., Babinski M., Artur A.C., Van Schmus W.R. 1996. Tectonic setting and U/Pb zircon dating of the plutonic Socorro Complex in the Transpressive Rio Paraíba do Sul Shear Belt, SE Brazil. Tectonics, 15(3):668-699.

Fernandes A.J., Campos Neto M.C., Figueiredo M.C.H. 1990. O Complexo Embú no leste do Estado de São Paulo: limites e evolução geológica. In: SBG, Congresso Brasileiro de Geologia. Natal, Anais, 6:2755-2763.

Fetter A.H., Hackspacker P.C., Ebert H.D., Dantas E.L., Costa A.C.D. 2001. New Sm/Nd and U/Pb geochronological constraints on the Archean to Neoproterozoic evolution of the Amparo basement complex of the central Ribeira belt, Southeastern Brazil. In: South American Synposium on Isotope Geology, 3. Santiago, Extend Abstracts (CD-ROM).

Freitas F.C. 2000. Geotermobarometria e evolução metamórfica das rochas granuíticas da região de Socorro-SP. Dissertação de Mestrado, Instituto de Geociências, Universidade de São Paulo, São Paulo, 175 p.

Frost B.R., Barnes C.G., Collins W.J., Arculus R.J., Ellis D.J., Frost C.D. 2001. A geochemical classification for granitic rocks. Journal of Petrology, 42(11):2033-2048

Garcia M.G.M. \& Campos Neto M.C. 2003. Contrasting metamorphic conditions in the Neoproterozoic collisionrealted nappes, South of São Francisco Craton, SE Brazil. Journal of South American Earth Sciences, 15(8):853-870. 
Gomes C.B. 1984. Microssonda eletrônica: princípios e aplicações na geologia. In: GOMES C.B. (ed.) Técnicas analíticas aplicadas à geologia. São Paulo, Edgar Blücher /Pró-Minério, p. 159-208.

Hackspacher P.C., Fetter A.H., Ebert H.D., Janasi V.A., Dantas E.L. Oliveira M.A.F., Braga I.F., Negri F.A. 2003. Magmatismo há ca. 660-640 Ma no Domínio Socorro: registros de convergência précolisional na aglutinação do Gondwana Ocidental. Geologia USP, Série Científica, 3:85-96.

Haddad R.C. 1995. O Batólito Granitóide Pinhal-Ipuiuna (SP-MG): Um exemplo do magmatismo cálcio-alcalino potássico neoproterozoico no sudeste brasileiro. Tese de Doutorado, Instituto de Geociências, Universidade de São Paulo, São Paulo, 256 p.

Heilbron M., Pedrosa-Soares A.C., Campos Neto M., Silva L.C., Trouw R.A.J., Janasi V.C. 2004. A Província Mantiqueira. In: Mantesso-Neto V., Bartorelli A., Carneiro C.D.R., Brito Neves B.B. (eds.) O desvendar de um continente: a moderna geologia da América do Sul e o legado da obra de Fernando Flávio Marques de Almeida. São Paulo, Beca, p. 203-234.

Heilbron M., Valeriano C.M., Tassinari C.C.G., Almeida J.C.H., Tupinambá M., Siga Junior O., Trouw R.A.J. 2008. Correlation of Neoproterozoic terranes between the Ribeira Belt, SE Brazil and its African counterpart: comparative tectonic evolution and open questions. In: Pankhurst R.J., Trouw R.A.J., Brito-Neves B.B., de Wit M. (eds.) West Gondwana pre-Cenozoic Correlations across the South Atlantic Region. London, Geological Society, Special Publications, 294:211-232.

Holland T. \& Blundy J. 1994. Non-ideal interactions in calcic amphiboles and their bearing on amphiboleplagioclase thermometry. Contributions to Mineralogy and Petrology, 116(4):433-447.

Janasi V.A. 1999. Petrogênese de granitos crustais na Nappe de Empurrão Socorro Guaxupé (SP-MG): uma contribuição da geoquímica elemental e isotópica. Tese de Livre Docência, Instituto de Geociências, Universidade de São Paulo, São Paulo, 304 p.

Janasi V.A., Alves A., Vlach S.R.F., Leite R.J. 2003. Granitos peraluminosos da porção central da Faixa Ribeira, Estado de São Paulo: Sucessivos eventos de reciclagem da crosta continental no Neoproterozóico. Geologia USP, Série Científica, 3(1):13-24.

Leake B.E. 1997. Nomenclature of amphiboles: report of the subcommittee on amphiboles of the International Mineralogical Association Commission on New Minerals and Mineral Names. European Journal of Mineralogy, 9:623-651.

Leonardos Júnior O.H. \& Fyfe W.S. 1974. Ancient metamorphicmigmatite belts of the Brazilian Atlantic coast: the African conection. Revista Brasileira de Geociências, 4:247-252.

Mantovani M.S.M. \& Brito Neves B.B. 2005. Geophysical boundaries of Paranapanema Proterozoic blocks: its importance for the Rhodinia to Gondwana evolutionary theories. Gondwana Research, 8(3):303-315.

Mantovani M.S.M., Quintas M.C.L., Shukowsky W., Neves B.B.B. 2003. Geophysical definition of Paranapanema Proterozoic block and its importance for the Rhodinia to Gondwana evolutionary theories. In: EGS AGU EUG Joint Assembly, Nice - France. EGS AGU EUG Joint Assembly. Paris, European Geophysical Society.

Matos G.C. 2008. A evolução estrutural, o metamorfismo e o magmatismo neoproterozóico de uma área que abrange as folhas Itajubá e Delfim Moreira, sul de MG. Dissertação de Mestrado, Instituto de Geociências, Universidade Federal do Rio de Janeiro, Rio de Janeiro, $97 \mathrm{p}$.

Middlemost E.A.K. 1985. Magmas and magmatic rocks: an introduction to Igneous Petrology. London, Harlow Longman Group Limited, $266 \mathrm{p}$.
Miller C.F., Mcdowell S.M., Mapes E.W. 2003. Hot and cold granites? Implications for zircon saturation temperatures and preservation of inheritance. Geology, 31(6):529-532.

Negri F.A. \& Oliveira M.A. 2005. Geoquímica e Geotermimetria dos Granulitos Máficos Associados às Rochas Supracrustais da Extremidade Meridional do Domínio Socorro, Região de São Francisco Xavier, SP. Revista Brasileira de Geociências, 35(4):591-602.

Negri F.A. 2002. Petrologia das rochas charnockitograníticas e encaixantes de alto grau associadas na região de São Francisco Xavier, SP. Tese de Doutorado, Instituto de Geociências e Ciências Exatas, Universidade Estadual Paulista, Rio Claro, 404 p.

Oliveira M.A.F. \& Ruberti E. 1979. Granada-cordierita gnaisses do complexo migmatítico de São José do Rio Pardo - Caconde, SP. Boletim de Mineralogia, 6:15-29.

Peternel R.M.N. 2005. A zona de superposição entre as Faixas Brasília e Ribeira na região entre Caxambu e Pedralva, sul de Minas Gerais. Tese de Doutorado, Instituto de Geociências, Universidade Federal do Rio de Janeiro, Rio de Janeiro, 257 p.

Shand S.J. 1943. The eruptive rocks. $2^{\text {nd }}$ ed. New York, John Wiley, $444 \mathrm{p}$.

Schmidt M.W. 1992. Amphibole composition in tonalite as a function of pressure:an experimental calibration of the Al-in-hornblende barometer. Contributions to Mineralogy and Petrology, 110:304-310.

Streckeisen A.L. 1976. Classification and Nomenclature of Plutonic Rocks. Recommendations of the IUGS Subcommission on the Systematics of Igneous Rocks. Geologische Rundschau. Internationale Zeitschrift for Geologie, 63:773-785.

Tavares F.M. 2008. Evolução Geotectônica da Região de Santa Rita. Dissertação de Mestrado, Instituto de Geociências, Universidade Federal do Rio de Janeiro, Rio de Janeiro, 107 p.

Trouw C.C. 2008. Mapeamento da Folha Virgínia-MG, Geocronologia U-Pb (SHRIMP) em zircão e interpretação geotectônica. Tese de Doutorado, Instituto de Geociências, Universidade Federal do Rio de Janeiro, Rio de Janeiro, 126 p.

Trouw R.A.J., Heilbron M., Ribeiro A., Paciullo F.V.P., Valeriano C.M., Almeida J.C.H., Tupinambá M., Andreis R.R. 2000. The central segment of the Ribeira belt. In: Cordani U.G., Milani E.J., Thomaz Filho A., Campos D.A. (eds.) Tectonic Evolution of South America. Rio de Janeiro, 31th International Geological Congress, p. 287-310.

Trouw R.A.J., Peternel R., Ribeiro A., Heilbron M., Vinagre R., Duffles P., Trouw C.C., Fontainha M., Kussama H. 2013. A new interpretation for the interference zone between the Southern Brasília Belt and the Central Ribeira Belt, SE Brazil. Journal of South American Earth Sciences, 48:43-57.

Vasconcellos A.C.B., Harris N.B.W., Tindle A.G. 1991. The relationship between metamorphism and tectonics: evidence from the SocorroGuaxupé Thrust Nappe, southeastem Brazil. In: Tulsku P., Laajaki K. (eds.) Metamorphism, deformation and structure of the crust. Oulu, The University of Oulu, Revista Terras, 5:86.

Vinagre R. 2014. O Batólito Serra da Agua Limpa, parte do Arco Magmático da Nappe Socorro-Guaxupé, Faixa Brasília Meridional. Tese de Doutorado, Instituto de Geociências, Universidade Federal do Rio de Janeiro, Rio de Janeiro, 270 p.

Vinagre R., Trouw R.A.J., Mendes J.C., Duffles P., Peternel R., Matos G. 2014. New Evidence of a Magmatic Arc in the Southern Brasília Belt, Brazil: The Serra da Água Limpa Batholith (Socorro-Guaxupé Nappe). Journal of South American Earth Science, 54:120-139.

Vlach S.R. \& Gualda G.A.R. 2000. Micropobe monazite dating and the ages of some granitic and metamorphic rocks from southeastern Brazil. Revista Brasileira de Geociências, 30:214-218. 
Watson E. B. \& Harrison T. M. 1983. Zircon saturation revisited: temperature and composition effects in a variety of crustal magma types. Earth and Planettary Science Letters, 64:295-304.

Wilson M. 1991. Igneous Petrogenesis: a global tectonic approach. London, Harper Collins Academic, 466 p.

Winter J.D. 2010. Principles of igneous and metamorphic petrology. 2a edição. New York, Prentice Hall, 702 p.
Wyllie P.J. 1981. Plate tectonics and magma Genesis. Geologische Rundschau, 70:128-153.

Wyllie P.J. 1984. Constraints imposed by experimental petrology on possible and impossible magma sources and products. Philosophical Transactions of the Royal Society of London, 310(1514):439-456.

Arquivo digital disponível on-line no site www.sbgeo.org.br 